Portland State University

PDXScholar

\title{
Characterization of Li-air batteries: Lithium Peroxide Formation in Li-air Electrodes
}

\author{
Claudia Torres Garibay \\ Oregon Institute of Technology \\ Jeremiah Deboever \\ Oregon Institute of Technology
}

Follow this and additional works at: https://pdxscholar.library.pdx.edu/trec_reports

Part of the Electrical and Computer Engineering Commons Let us know how access to this document benefits you.

\section{Recommended Citation}

Garibay, Claudia Torres, and Jeremiah Deboever. Characterization of Li-air batteries: Lithium Peroxide Formation in Li-air Electrodes. NITC-SS-735. Portland, OR: Transportation Research and Education Center (TREC), 2014. https://doi.org/10.15760/trec.78

This Report is brought to you for free and open access. It has been accepted for inclusion in TREC Final Reports by an authorized administrator of PDXScholar. Please contact us if we can make this document more accessible: pdxscholar@pdx.edu. 


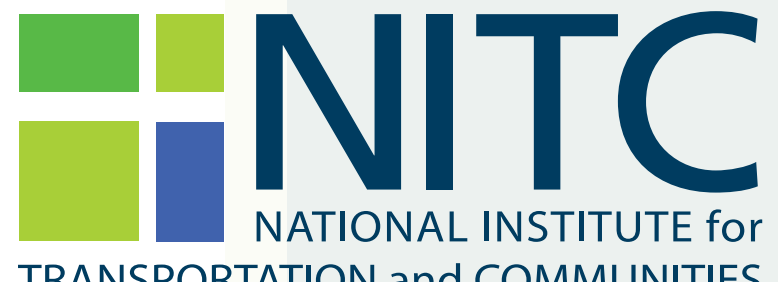

TRANSPORTATION and COMMUNITIES

FINAL REPORT

Characterization of Li-air batteries: Lithium Peroxide Formation in Li-air Electrodes

NITC-SS-735 June 2014

NITC is the U.S. Department of Transportation's national university transportation center for livable communities.

H:"TREC 


\title{
CHARACTERIZATION OF LI-AIR BATTERIES LITHIUM PEROXIDE FORMATION IN LI-AIR ELECTRODES
}

\author{
Final Report \\ NITC-SS-735
}

by

Claudia Torres Garibay (PI) and Jeremiah Deboever

Oregon Institute of Technology

for

Oregon Transportation Research

and Education Consortium (OTREC)

P.O. Box 751

Portland, OR 97207

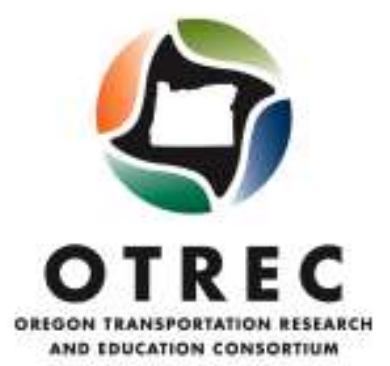

June 2014 



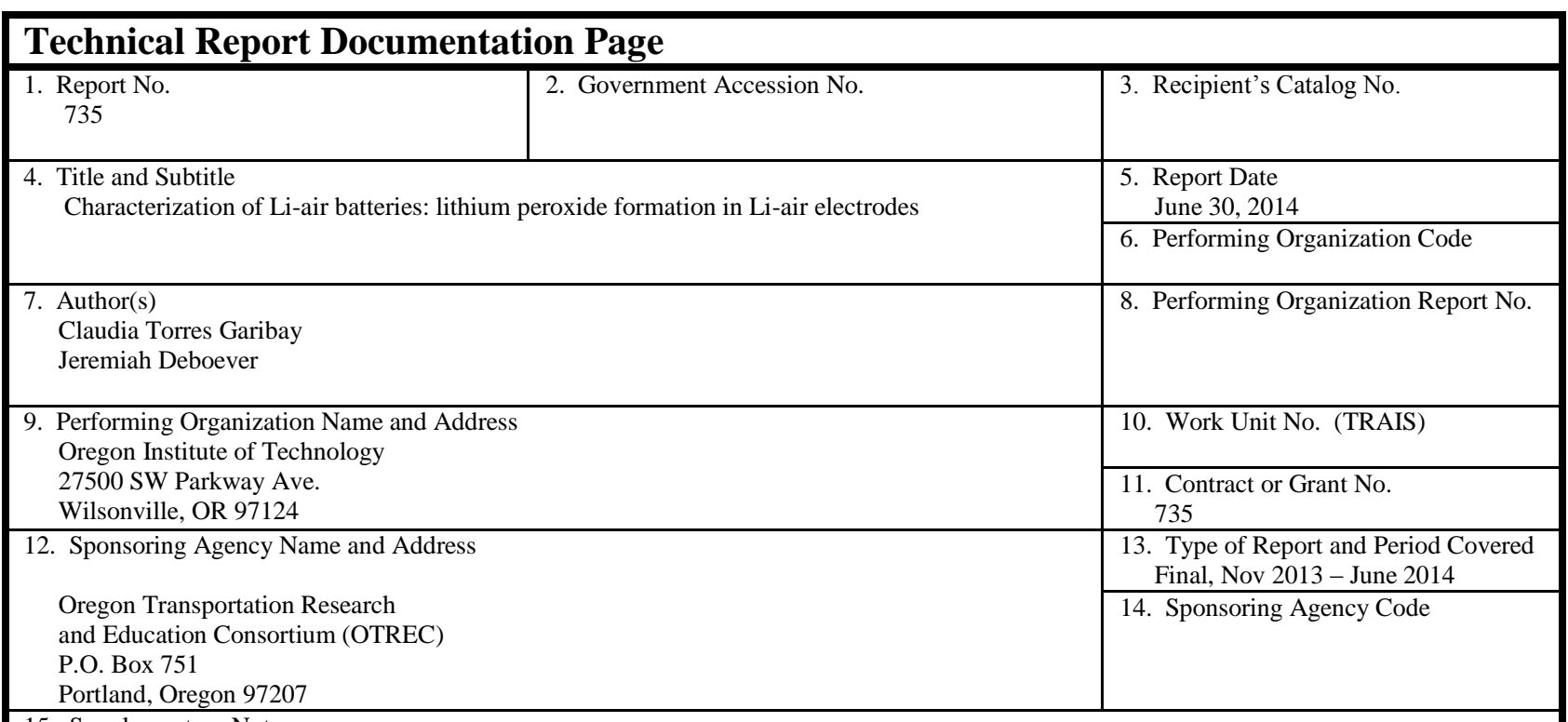

15. Supplementary Notes

16. Abstract

Li-air batteries are attractive candidates to be used in electric vehicles (EV) due to their high theoretical capacity, which results in an improved range, a requirement to make EV competitive against fossil fuel powered vehicles. However, Li-air battery technology is considered to be far from commercialization, due to its short lifespan. The decomposition of the electrolyte and its effect on cyclablity has been widely studied, no so much the cathode. This work will make use of recently reported novel adaptation of titration techniques to study cathode degradation in Liair batteries, along capacity, cyclability, and EIS studies, to characterize the effect of different carbon materials used as cathodes in Li-air batteries.

\begin{tabular}{|c|c|c|c|c|}
\hline \multicolumn{2}{|c|}{$\begin{array}{l}\text { 17. Key Words } \\
\text { Li-air batteries, carbon cathode characterization, peroxide titration, EIS }\end{array}$} & \multicolumn{3}{|c|}{$\begin{array}{l}\text { 18. Distribution Statement } \\
\text { No restrictions. Copies available from OTREC: } \\
\text { www.otrec.us }\end{array}$} \\
\hline $\begin{array}{l}\text { 19. Security Classification (of this report) } \\
\text { Unclassified }\end{array}$ & $\begin{array}{l}\text { 20. Security Classificati } \\
\text { Unclassified }\end{array}$ & page) & $\begin{array}{l}\text { 21. No. of Pages } \\
49\end{array}$ & 22. Price \\
\hline
\end{tabular}





\section{ACKNOWLEDGEMENTS}

The authors would like to thank the members of the ODOT Research Unit for their advice and assistance in the preparation of this report, as well as the support and advice of Dr. Edward Nasybulin from PNNL, and Dr. Slobodan Petrovic from Oregon Tech.

\section{DISCLAIMER}

The contents of this report reflect the views of the authors, who are solely responsible for the facts and the accuracy of the material and information presented herein. This document is disseminated under the sponsorship of the U.S. Department of Transportation University Transportation Centers Program and the National Institute for Transportation and Communities in the interest of information exchange. The U.S. Government and the National Institute for Transportation and Communities assumes no liability for the contents or use thereof. The contents do not necessarily reflect the official views of the U.S. Government and the National Institute for Transportation and Communities. This report does not constitute a standard, specification, or regulation. 



\section{TABLE OF CONTENTS}

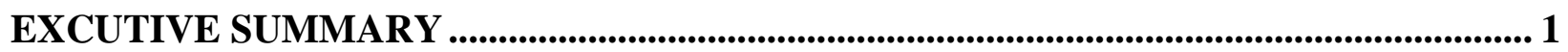

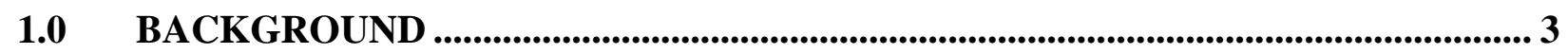

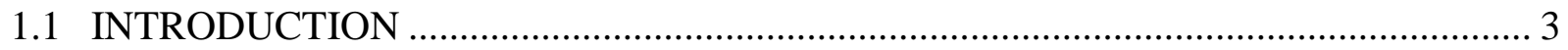

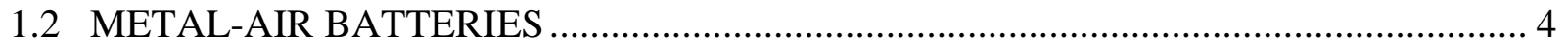

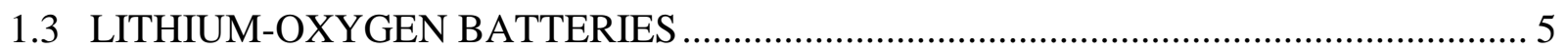

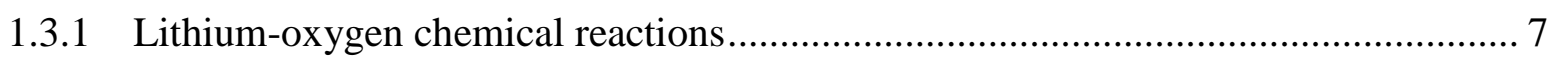

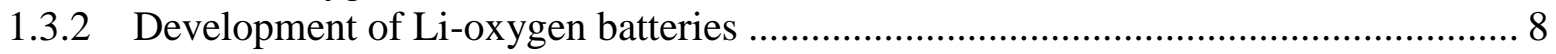

1.3.2.1 Lithium Electrolyte ..................................................................................... 9

1.3.2.2 Electrolyte Composition.................................................................................. 9

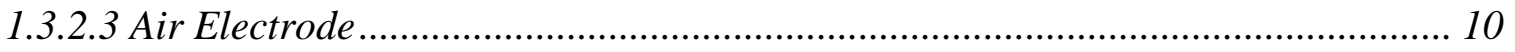

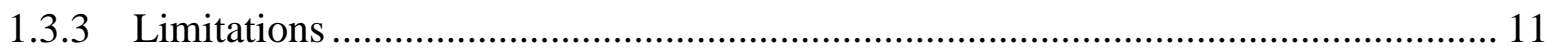

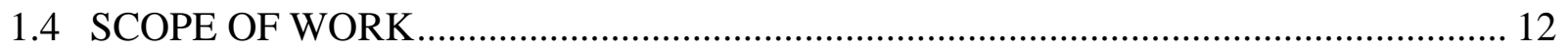

2.0 EXPERIMENTAL SETUP ............................................................................... 13

2.1 CATHODE PREPARATION INSTRUMENTS ………............................................ 13

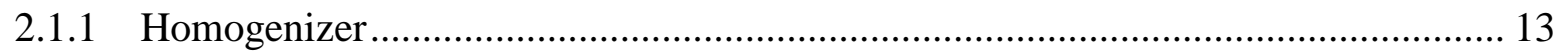

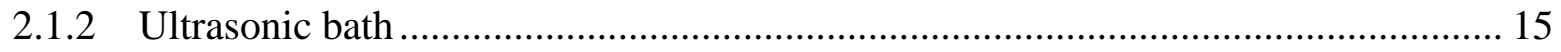

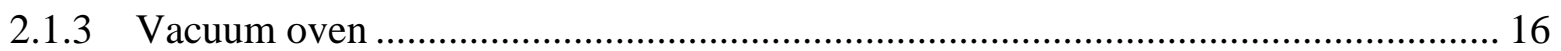

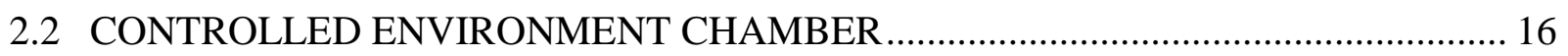

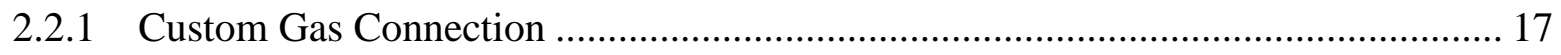

2.2.2 Gas Monitoring Instruments ………………................................................ 18

2.2.3 System Performance Improvements ...................................................................... 19

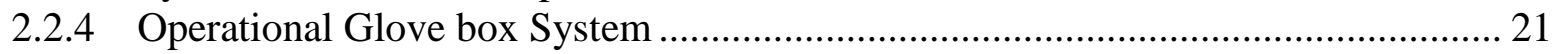

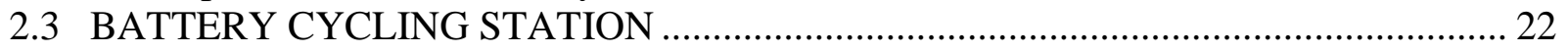

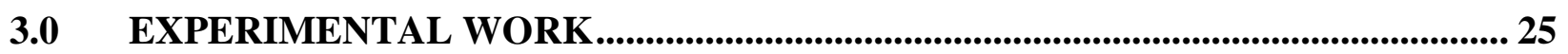

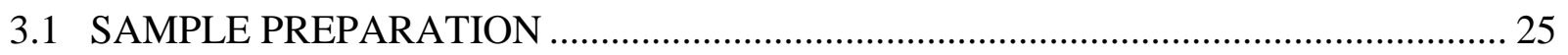

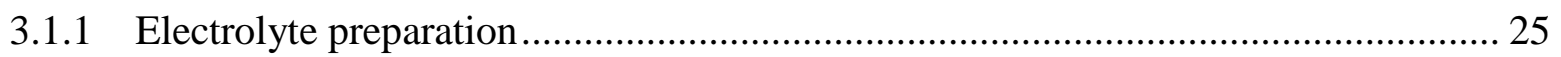

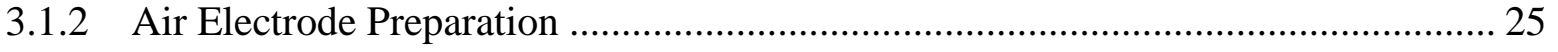

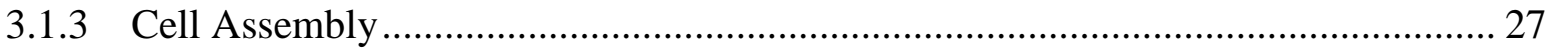

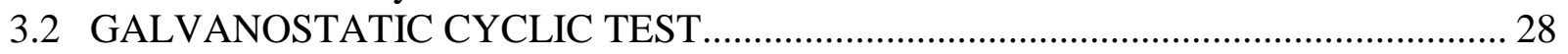

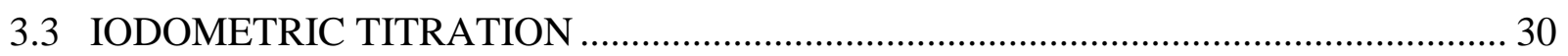

3.4 ELECTROCHEMICAL IMPEDANCE SPECTROSCOPY ……………………............ 32

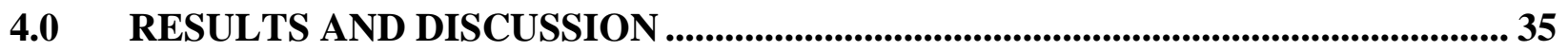

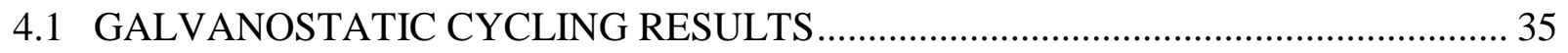

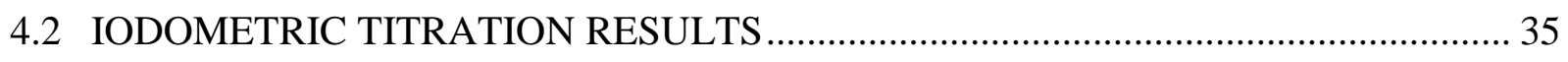

4.3 ELECTROCHEMICAL IMPEDANCE SPECTROSCOPY RESULTS............................ 35

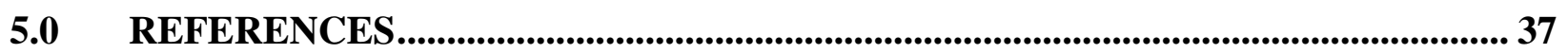

\section{LIST OF TABLES}

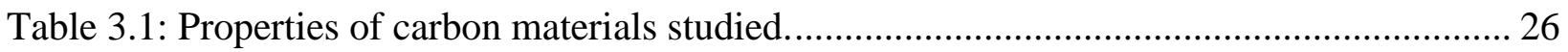

Table 3.2: Optimized mixing ratios for carbon electrode slurries. ................................................. 26 


\section{LIST OF FIGURES}

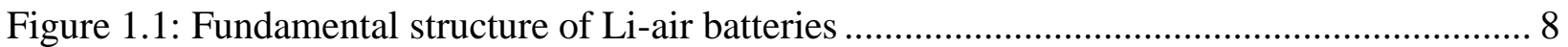

Figure 2.1: IKA T-18 Basic Homogenizer commercially available from Cole Parmer. ............... 14

Figure 2.2: Custom Homogenizer. Outfitted Dremel on its stand (left). 1/8th SS mixing bit (right).

Figure 2.3: Binder solutions showing the introduction of impurities when a 1/4" SS guard was used.

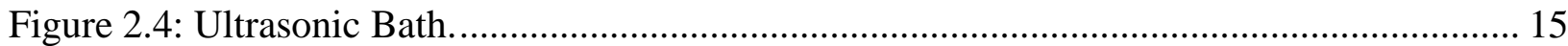

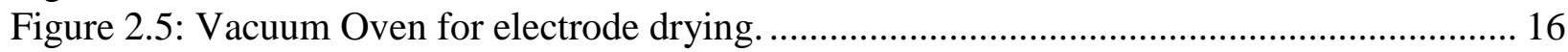

Figure 2.6: Simplified glove box layout with working pressures............................................... 17

Figure 2.7: Three-way valve used to purge the lines before connecting a new gas tank. Currently

allowing flow from the Ar tank to the working chamber.

Figure 2.8: Three-way valve used to manually control the transfer chamber pressure. Currently allowing the flow from the vacuum pump to the transfer chamber.

Figure 2.9: (a) Custom Moisture Filter System for the glove box. (b) Metal mesh to contain the desiccant material. (c) $3 \mathrm{~W}$ computer fan. ...................................................................... 20

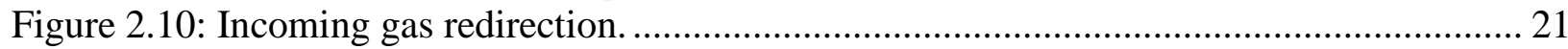

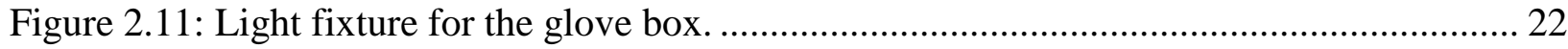

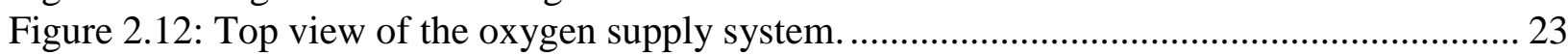

Figure 3.1: Cross-section assembly of a Swagelok cell design. (1- Air cathode, 2-

Spacer/electrolyte, 3- Lithium Anode, 4- Stainless Steel Spacer, A- Swagelok PFA Union, B- PFA ferrule set, C- Stainless Steel rod, D- Stainless Steel Spring, E- Stainless Steel

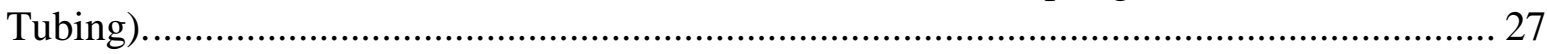

Figure 3.2: Fully Assembled Swagelok Cell connected to the oxygen supply system................. 28 Figure 3.3: Voltage profile of a cell discharged down to $1.5 \mathrm{~V}$ showing the reaction potentials.

The dashed red line shows the redox potential of lithium. .................................................. 29

Figure 3.4: Voltage profile of a charge cycle showing the reaction potentials. The dashed red line

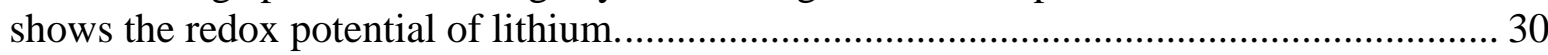

Figure 3.5: Equivalent circuit of all connections in an assembled Swagelok cell ........................ 33 


\section{EXCUTIVE SUMMARY}

Lithium-oxygen batteries have attracted attention in the last decade for their remarkable theoretical capacities. Valuable efforts have increased the initial discharge capacity to over 10 times that of conventional lithium-ion batteries. However, cells have yet demonstrated to be rechargeable as the internal reactions are highly unstable. The oxygen-rich environment in combination with a wide potential window and the presence of lithium promote uncontrolled and irreversible reactions in the cell. The chemistry and components of aprotic lithium-oxygen (also known as Li-air) battery cells are explored in this report. The need to understand the effect of different carbon materials as cathode candidates motivates the study of the decomposition mechanisms at the cathode. While the practical implementation of Li-air batteries in EV requires much more development and understanding of this technology, this study aims to contribute to the basic understanding on the factors influencing the short lifespan of these cells at the laboratory level.

In order to be able to conduct a characterization study on Li-air batteries, an experimental laboratory station was setup at Oregon Tech Wilsonville campus with the funds provided by this grant. The cathode preparation station included a homogenizer, ultrasonic bath, and vacuum oven. A glove box was converted into a controlled environment chamber by installing a customized gas connection, oxygen and moisture sensors, moisture purification system, analytical balance, and a light fixture. Batteries were tested in a cycling station consisting of an 8-channel potentiostat, computer, and gas supply system.

This work explores the mechanisms behind the various complex reactions at the cathode of Liair batteries. The targeted reaction results in the formation of reversible lithium peroxide $\left(\mathrm{Li}_{2} \mathrm{O}_{2}\right)$. The characterization of lithium peroxide formation in lithium air electrodes is performed via titration techniques and Electrochemical Impedance Spectroscopy (EIS). Various carbon materials with different surface area and pore volumes were evaluated in cathodes for Li-air batteries. Their performance was correlated to the discharge product yield and the impedance spectrum of the cell. Three testing techniques, life cycle testing, $\mathrm{Li}_{2} \mathrm{O}_{2}$ titration and electrochemical impedance spectroscopy, provided the different perspectives on the complex chemical mechanisms in lithium-oxygen batteries. The results and conclusions of this work are explained in detail in a thesis presented to obtain the degree of Masters in Science in Renewable Energy Engineering during Summer 2014. 


\subsection{BACKGROUND}

\subsection{INTRODUCTION}

The need of energy storage when using renewables rises from the variability and unpredictability of the natural sources of energy. Although multiple types of energy storage systems exist, electrochemical energy storage has been highly sought after for their versatility in implementation, high energy densities and overall efficiency. One of the driving forces to this field has been the automotive industry with hybrid and electrical vehicles (HVs and EVs) requiring light and long-lasting energy storage. By taking advantage of efficient and quieter electrical motors, EVs offers a number of benefits compared to conventional petroleum-based vehicles. Emissions due to transportation are drastically diminished when recharging the energy storage system through the cleaner power of the grid. However, the limiting factors to this promising transportation change are the state-of-the-art energy density, efficiency and life cycle of energy storage system [1]. Although subsidies from petroleum companies are still limiting the push of electric vehicles, the interest from consumers has recently helped raise funding for energy storage research.

As a consequence of this growing need in the automotive industry as well as within the national electrical grid, various research initiatives in the U.S. have been established over the last decade. A few programs from the Advanced Research Projects Agency - Energy (ARPA-E) within the Department of Energy (DOE) have supported research groups in energy storage across the country [2]. The Battery for Electrical Energy Storage in Transportation (BEEST) program has for objective of meet or beat the performance and price of petroleum vehicles to enable large penetration of EVs [3]. A more recent collaborative program funded by the DOE Energy Innovation Hub - Batteries and Energy Storage is the Joint Center for Energy Storage Research (JCESR) [1]. Based off the Argonne National Laboratory in Illinois, the objective of JCESR is to investigate viable research projects and bring any optimistic results as close as possible to market. To achieve this goal, a roadmap consisting of four stages (Electrochemical Storage Concepts, crosscutting science, systems analysis and translation, cell design and prototyping) was set to clarify viable technologies and combine efforts towards moving those technologies forward. Any projects funded by the center enter into an agreement that defy one of the academic downfalls: inter-group collaboration. Thus, the growing interest followed by various means of financial support has made the field of next generation energy storage very promising.

Prior to going into the state-of-the-art, a brief introduction of the relevant research milestones that have shaped the batteries of today is presented [4]. The first reported chemical battery was the voltaic pile developed in 1800 by Alessandro Volta. Sixty years later, Gaston Plante discussed about the first practical battery: the lead acid storage battery and it takes nearly a century later for Waldemar Junger and Karl Berg to develop an alternative chemistry: the first nickel-cadmium battery. While various electrochemical storage are being developed, Evereday Battery Company develops the first widely used $9 \mathrm{~V}$ battery in 1956. It is not until 1979 that 
John Goodenough at Oxfords perfects the first lithium ion battery - Lithium Cobalt Oxide and Lithium Manganese Dioxide. Besides this major scientific breakthrough, Sony was the first company to commercialize the technology. Seventeen years later, Goodenough further improves the stability of lithium ion batteries with the lithium iron phosphate battery. In consequence, over the last few decades, the energy density of lithium-ion batteries has made them highly desirable for commercialization products. Over the last 35 years, their energy density has only been improving on average 5\% every year and their theoretical values has been very closely approached $[4,5]$. To meet future needs, efforts have been focused on the next generation of batteries - aka 'beyond lithium-ion' batteries.

Increasing the performance of electrochemical energy storage systems has been sought for a few decades by many different groups. Current graphite-based lithium cells have been one of the most popular chemical batteries both on the market and from the research stand point. However, the maximum theoretical capacity $(400 \mathrm{Wh} / \mathrm{g}, 250 \mathrm{mAh} / \mathrm{g}$ [5]) that can be achieved still falls short of the possible future goals set by the US DOE and DOD (Department of Defense). As a matter of fact, the current rate of capacity improvement is only 5\% a year which falls short of the 2020 goal set by JCESR [1].

While lithium ion batteries have a limit on their optimization that most likely will not meet our future needs, researchers have been focused on novel chemistries beyond lithium ion batteries. The JCESR highlights four research directions that may meet future needs [1]. The first one is multivalent ion intercalation in conventional chemistries. By replacing the monovalent lithium ion with a multivalent element such as magnesium or aluminum, the capacity stored can double or triple depending on the chemistry. The second concept is to replace solid electrodes with liquid solutions or suspensions. A current example of this concept are redox flow batteries. The third concept is 'designer organic molecules' used to create tailored structure-function relationships (Solid electrolyte interface (SEI) layers, redox couples, ...). The last concept highlighted by JCESR is the one this work is most focused into: chemical transformation. The objective of this approach is to investigate traditional intercalation with high energy chemical reactions. Chemistries such as sodium-sulfur, lithium-sulfur or metal-air can provide a greatly improved energy density and possibly justify the incorporation of energy storage in high energy demand technologies with weight and volumetric limitations (i.e. electrical vehicle).

\subsection{METAL-AIR BATTERIES}

A number of currently researched chemistries for novel electrochemical energy storage have been categorized as metal air batteries. The interest is from the highly reactive alkali metals in air. If these reactions are controlled, a very large amount of energy can be harvested from them. From least to most reactive, pure lithium-sodium-potassium-rubidium-cesium-francium metals can undergo drastic reactions when exposed to water, halogens, nitrogen, oxygen or hydrogen gas. The most commonly known is the reaction with water since alkali metals will spontaneously form a strong aqueous base $\left(\mathrm{OH}^{-}\right)$and hydrogen gas as shown in Equation 1-1.

$$
2 \mathrm{M}_{(s)}+2 \mathrm{H}_{2} \mathrm{O} \rightarrow 2 \mathrm{MOH}_{(a q)}+\mathrm{H}_{2(g)}
$$


Where $\mathrm{M}$ is an alkali metal. The exothermic behavior of this reaction increases when going down in the group IA of the periodic table, thus explaining the explosive nature of the reaction with high concentration of hydrogen gas. This violent reaction with water can hardly be controlled electrochemically. When alkali metals are combined with oxygen gas, the product of the reaction can be various forms of oxide, peroxide and superoxide compounds, some being more stable than others. In contrast to water, this reaction can be electrochemically controlled and the products are relatively reversible in some cases. The advantage of this reaction over conventional ionic intercalation is that it utilizes a reactant stored externally and that the reaction has a theoretical energy density not limited by maximum ionic intercalation.

Conventional lithium ion batteries are based on an ionic intercalation principle that take advantage of the small size of $\mathrm{Li}$ atom $(0.9 \AA$ [6]). Used in one or both electrodes, intercalation compounds have a structure into which lithium ions can be intercalated and removed upon discharge and charge, respectively [6]:

$$
x L i+M_{z} B_{y} \leftrightarrow L i_{x} M_{z} B_{y}
$$

Where $\mathrm{M}_{\mathrm{z}} \mathrm{B}_{\mathrm{y}}$ is the transition metal compound. In other words, as the cell is being discharged, lithium ions formed at the negative electrode (anode) migrate to the positive electrode (cathode) and enter the crystalline structure of the metal compound. Upon the charging cycle, the reaction reverses and lithium ions exit the crystalline structure of the cathode material. Thus, the available intercalation sites ratio of the host material affect the overall theoretical capacity of conventional lithium ion batteries. Goodenough further discusses the difficulties associated with the lithium transport in batteries based on lithium-insertion compounds [7]. Various crystalline structures, such as layered, spinel or olivine framework structures, have been investigated to mitigate this limitation though improvement in the energy density has been limited [8].

In contrast, metal-air batteries utilize a low carbon packing porous carbon that allow diffusion of oxygen and leaves extensive reaction sites for discharge products to form, which increases the overall energy density of the material. Zheng et al investigate more specifically the theoretical energy density of one of the metal-air chemistries - lithium-oxygen - in terms of the porosity of the cathode material [9].

\subsection{LITHIUM-OXYGEN BATTERIES}

There are four chemistry architectures of lithium-oxygen batteries that are currently pursued in research: aprotic, aqueous, mixed-electrolyte and fully solid-state batteries [10]. The first three architectures are in the liquid form while the last one is in the solid form. Aqueous and mixedelectrolyte lithium oxygen cells take advantage of the highly reactive reaction of lithium with water as previously described. However, an additional layer must be used to protect the lithium from spontaneously reacting. For this reason, as well as others later discussed, the work proposed in this work will mainly focus on aprotic reactions.

The highest theoretical specific capacity of lithium-air cells is $3862 \mathrm{mAh} / \mathrm{g}$ [6]. With the high voltage of $2.9-3.1 \mathrm{~V}$ of lithium, the theoretical specific energy of Li-air cells for non-aqueous exceeds $11,000 \mathrm{Wh} / \mathrm{kg}$ as shown in Equation 1-3. 


$$
E=\frac{V F}{m}=\frac{(3 \mathrm{~V})(96,500 \mathrm{C} / \mathrm{mol})}{6.9 \mathrm{~g} / \mathrm{mol}} * \frac{1 \mathrm{Ah}}{3600 \mathrm{C}}=11,700 \frac{\mathrm{Wh}}{\mathrm{kg}}
$$

Where $\mathrm{E}$ is the specific energy, $\mathrm{V}$ is the voltage of the cell, $\mathrm{F}$ is the Faraday Constant, and $\mathrm{m}$ is the molecular mass of Li. In comparison with commercial batteries, Li-air batteries become an obvious interest of research even if theoretical values are not reached. However, this remarkable 10 fold increase of the energy density is only considering the potential of the lithium anode without any other present constraints. Thus, an adequate estimation of the theoretical energy capacity potential of lithium oxygen cell must take into account the properties of the electrolyte and the counter electrode. Zheng et al presented in 2008 practical maximum theoretical specific energies of $1300 \mathrm{Wh} / \mathrm{kg}$ and $1400 \mathrm{Wh} / \mathrm{kg}$ for aqueous cells where the weight of the basic and acidic electrolytes, respectively, were considered in the calculations [9]. The paper uses for comparison the practical theoretical specific energy for non-aqueous Li-air batteries with an organic electrolyte at $2790 \mathrm{Wh} / \mathrm{kg}$, which is lower than the value in Eq. 1-3. Nonetheless, the estimation is still a 10 fold improvement on the state-of-the-art lithium ion batteries. This theoretical approach investigates the feasible theoretical energy properties of the chemistry in terms of the porosity of the carbon material - which relates to the maximum capacity of lithium ion batteries being limited by their intercalation capabilities. Even though practical values are far from the estimated theoretical densities, these estimations remain relatively high in contrast to current batteries. Experimental energy densities for the different lithium-oxygen reactions are discussed later in this report. Moreover, Zheng et al discuss about another cell property that is especially important in lithium-oxygen cells, that is of the volumetric capacities. Based on the minimum volume of air electrode required for the electrochemical reaction to occur, the maximum calculated volumetric energy densities are $1520 \mathrm{Wh} / \mathrm{L}, 1680 \mathrm{Wh} / \mathrm{L}$ and $2800 \mathrm{Wh} / \mathrm{L}$ in basic, acidic and organic electrolyte, respectively [9]. However, a presentation at the Almaden Institute in 2009 presented a volumetric density of $3400 \mathrm{Wh} / \mathrm{L}$ for Li-air cells with organic electrolyte [11].The slight disagreement between these calculated values come from their difference in the porosity assumption (100\% and 70\%). More recently, a paper by Christensen et al demonstrated that the energy densities of different reactions categorized within lithium-air batteries are not as remarkable as the improvement seen on a specific energy stand-point [5].

Conventionally, the specific power of a cell is often inversely proportional to the energy density. Currently, prototype aprotic Li-air cells deliver power densities in the order of $1 \mathrm{~mA} / \mathrm{cm}^{2}$ [10], which is in the same order of magnitude as current lithium ion batteries [12]. The challenge that Li-air cells often face is that power available is proportional to the rate of oxygen diffusion into the cell [13]. It is common that high rate cells have a shorter service life [6]. This factor has also been observed in other metal air batteries such as zinc/air [6]. This is a very important area of discussion since the specific capacity of lithium ion cells is around $3-7 \mathrm{mAh} / \mathrm{cm}^{2}$ while $\mathrm{Li}-\mathrm{O}_{2}$ cells can approach $50 \mathrm{mAh} / \mathrm{cm}^{2}$ [5]. As a consequence, the practical power per unit of weight or volume decreases rapidly affecting the rate capability of high density electrode Thus, a balance between the electrode thickness and its current density has to be established for a practical application. 


\subsubsection{Lithium-oxygen chemical reactions}

The requirements for an electrochemical mechanism to be qualified as a lithium-oxygen battery are that lithium needs to react electrochemically with oxygen gas and that the absorbed oxygen gas is regenerated upon the reverse reaction. The nature of the reaction renders a complex mechanism of multiple reaction phases. As previously discussed, the presence of oxygen with an alkali metal can form three types of groups: oxide, superoxide and peroxide. In the present case of monovalent lithium, the following equations show the various oxidation states [14].

Lithium superoxide:

$$
2 \mathrm{Li}_{(s)}+2 \mathrm{O}_{2} \rightarrow 2 \mathrm{LiO}_{2} \quad \Delta G^{o}=-140 \mathrm{kcal} \quad\left(E^{o}=3.0 \mathrm{~V}\right)
$$

Lithium peroxide:

$$
2 \mathrm{Li}_{(s)}+2 \mathrm{O}_{2} \rightarrow \mathrm{Li}_{2} \mathrm{O}_{2} \quad \Delta G^{o}=-145 \mathrm{kcal} \quad\left(E^{o}=3.1 \mathrm{~V}\right)
$$

Lithium oxide:

$$
2 \mathrm{Li}_{(s)}+\frac{1}{2} \mathrm{O}_{2} \rightarrow \mathrm{Li}_{2} \mathrm{O} \quad \Delta G^{o}=-139 \mathrm{kcal} \quad\left(E^{o}=2.91 \mathrm{~V}\right)
$$

Each of these states has reduced number of oxygen moles used. This case is further illustrated when solely observing the oxygen reduction reactions:

Lithium superoxide:

$$
2 \mathrm{O}_{2}+2 e^{-} \rightarrow 2 \mathrm{O}_{2}^{-}
$$

Lithium peroxide:

$$
\mathrm{O}_{2}+2 e^{-} \rightarrow \mathrm{O}_{2}{ }^{2-}
$$

Lithium oxide:

$$
\frac{1}{2} O_{2}+2 e^{-} \rightarrow O_{2}^{-}
$$

The dynamic behavior of the oxygen reduction reaction (ORR) upon discharging is crucial to interpret any reaction mechanisms. As an excess of oxygen is present at the start of the ORR, lithium superoxide forms electrochemically as shown in Equation 1-4. Superoxide species in the presence of lithium ions are unstable and thus disproportionate or further reduces chemically as follows [14]:

$$
\begin{gathered}
2 \mathrm{LiO}_{2} \rightarrow \mathrm{Li}_{2} \mathrm{O}_{2}+\mathrm{O}_{2} \\
\mathrm{LiO}_{2}+\mathrm{Li}^{+}+e^{-} \rightarrow \mathrm{Li}_{2} \mathrm{O}_{2}
\end{gathered}
$$


Experimental work has been published showing lithium peroxide as intermediate species to the peroxide formation demonstrating the reaction mechanisms [15]. Further decomposition of lithium peroxide into oxide species has also been observed as the cell is discharge at lower voltages. A second plateau at $2.1 \mathrm{~V}$ has been documented to produce those species upon further reduction $[16,17]$ :

$$
2 \mathrm{Li}^{+}+\mathrm{Li}_{2} \mathrm{O}_{2} \rightarrow 2 \mathrm{Li}_{2} \mathrm{O}_{2} \quad E^{o}=2.72 \mathrm{~V}
$$

Although the formation of lithium oxide would minimize the quantity of oxygen required to be absorbed, the practical plateau at which it occurs $(\sim 2.1 \mathrm{~V})$ is not optimum for a reversible cycle considering the large voltage window that it would require. Moreover, the oxidation of lithium peroxide is considered as the only truly reversible reaction in aprotic cells. Thus, as for future reference, the desired reaction for lithium oxygen cell is assumed to be as described in Equation $1-5$.

\subsubsection{Development of Li-oxygen batteries}

A lithium-oxygen-like battery was first observed mistakenly in 1996 when Abraham et al witnessed an increase in capacity in a lithium ion pouch cell [18]. He later noticed that a tiny pinhole in the cell was allowing oxygen to enter the cell and react with the lithium. Nearly a decade later, Read investigated the reaction to discover the effect of oxygen diffusion on the rate capability and discharge capacity [13]. The same year, Peter Bruce and his group investigated the oxygen evolution in the aprotic lithium oxygen cell to confirm the reversibility of lithium peroxide [19]. The last research milestone of the lithium oxygen reaction was in 2010 when Mizuno et al questioned the formation of lithium peroxide in carbonate-based electrolyte solvent [20]. After analyzing the discharged products, carbonate species (lithium carbonate and lithium alkylcarbonate) were obtained correlating with the large voltage gap between the discharge and charge plateaus. Additional papers have been reviewed in this section to give a brief overview of each element comprised in a $\mathrm{Li}-\mathrm{O}_{2}$ cell, as demonstrated in Figure 1.1.

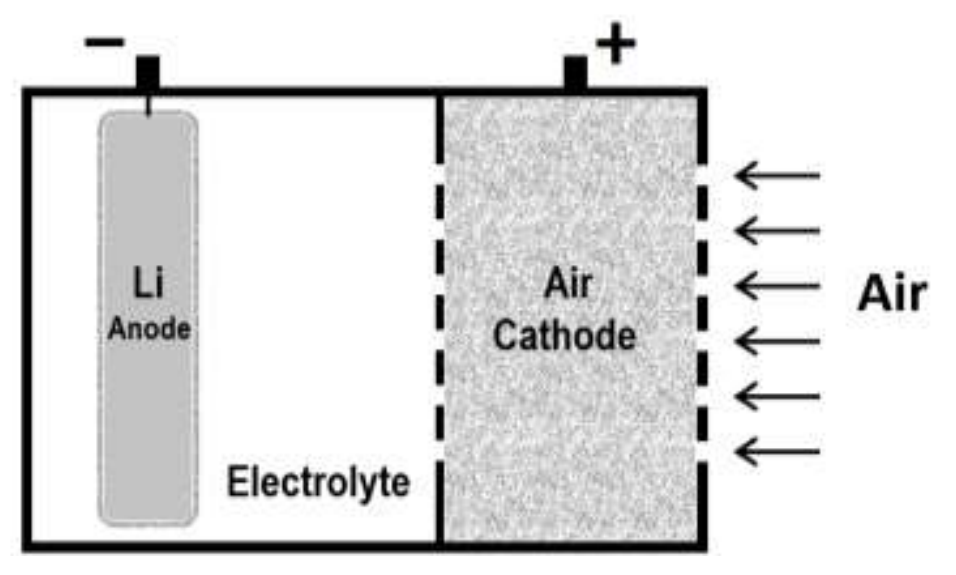

Figure 1.1: Fundamental structure of Li-air batteries 


\subsubsection{Lithium Electrolyte}

Lithium oxygen cells have a metallic lithium flat disc for the negative electrode to provide the electrochemical pathway for the transfer of ions in the electrolyte. During the discharge, lithium salts from the electrolyte are oxidized on the surface of the anode allowing the ions to travel through the electrolyte. The electrons travel through the electrical connection to the cathode to form lithium peroxide. The presence of lithium metal in a battery may not be suitable for commercialization but a stable system must first be achieved. Thus, the use of excess lithium metal allows focusing on the reactions at the cathode to establish a reversible system.

Nevertheless, research is still being pursued on the lithium electrode [21 - 23]. Lithium degradation and dendrite formation are two common concerns on the anode side of a lithium-oxygen cell. With high number of cycles, the progress of dendrites can create short-circuits between the cathode and the anode [24]. Furthermore, electrolyte incompatibility may lead to the formation of a resistive film barrier onto the anode [24] and reduce the diffusion of lithium ions. These two issues affect the cycle life and safety of the battery [24]. This topic is beyond the scope of this review; however, it is relatively well covered by the literature [21 - 23] and may be subject for possible future investigation.

\subsubsection{Electrolyte Composition}

Fundamentally speaking, batteries are required to have a layer between the positive and negative electrode. The key properties of this layer can be summarized as electrically insulating, chemically inert to the electrodes and ionicly conducting. Thus, in liquid electrolyte batteries, the layer is often comprised of a porous insulating separator and a liquid electrolyte. The latter is often composed of a solvent and a salt to create a good interconnection between the two electrodes and to allow the essential transfer of ions across the layer, respectively. Subject of a number of studies, the electrolyte composition has shown to have a large effect on the reaction in the cells and directly affect its reversibility [1]. Due to the large potential window of lithium-oxygen cell $(2.0 \mathrm{~V}-4.5$ $\mathrm{V})$, decomposition and alteration of the electrolyte is one of the causes that decreases the cell capacity with increasing number of cycles. Many approaches to the issue have been investigated (different solvent compositions, salt concentrations, small voltage window testing conditions, reduction of potential window using a catalyst, etc.) thought no breakthrough have been discovered.

The current compositions of liquid aprotic electrolytes can be categorized into carbonbased and noncarbonated solvents. Jake Christensen et al extensively elaborated on the two categories in the review published in 2012 [5]. Multiple publications are reviewed concluding that carbonate solvents, without the presence of any polymer, are not suitable for reversible reactions [5]. Side reactions (i.e. carbonates formation) through the first discharge process are disadvantageous to the battery chemistry since these reactions are often uncontrolled and reduce the reactant's availability [25]. Moreover, their nonreversibility and insulating effect are disadvantageous for the lithium-oxygen reaction. 
Noncarbonate solvents have shown more promise towards developing a reversible reaction in Li-oxygen battery. Three types of solvents are explored in Christensen et al's review [5]: ethers, ionic liquid, and acetonitrile. Ether-based solvents (i.e.

dimethoxyethane or DME) was demonstrated in the publication as unsuitable solvents to achieve a reversible reaction though further research with lower charging currents is recommended before removing ethers as a possible solution. Controversially, recent research from different stand-out active research groups [19, 25-29] continue to utilize ether-based solvents such as DME, N,N-dimethylacetamide (DMA), dimethyl sulfoxide (DMSO) or glymes to improve the properties of $\mathrm{Li}-\mathrm{O} 2$ cells.

$\mathrm{N}, \mathrm{N}$-dimethylacetamide (DMA) was recently demonstrated to "resist chemical degradation" in the harsh environment of the $\mathrm{O}_{2}$ electrode [28]. Although providing a remarkable quality that few other solvents have, straight-chain alkyl amides solvents are often affected on the lithium side of the reaction due to the unstable solid-electrolyte interphase (SEI) they create on the lithium anode [28]. However, the publication discusses how the addition of lithium nitrate salts stabilizes the SEI layer. With test cells reaching over 80 cycles at a current density of $0.1 \mathrm{~mA} / \mathrm{cm} 2$, the presented results demonstrates a possible viability of using ether-based solvents in $\mathrm{Li}_{-} \mathrm{O}_{2}$ batteries. Similarly, DME is another solvent that has shown to form lithium peroxide upon discharge in a relatively reversible manner [30]. Glyme-based electrolytes have shown to have a relatively stable chemistry that do not require an additive to stabilize it in lithiumair batteries [14, 15, 27, 31,32]. Moreover, solvents with low donor number such as tetraethylene glycol dimethyl ether (TEGDME) are more prone to fully reduce $\mathrm{O}_{2}$ to $\mathrm{O}_{2}$ [14].

Electrolyte salts have also shown to have an effect on the stability of the cells [27]. A research by Nasybulin published in January 2013 shows the different performance of salts in a $1.0 \mathrm{M}$ glyme-based electrolyte [27]. Seven salts were assessed using TEGDME as the electrolyte solvent and KetjenBlack as the carbon electrode. The study investigates the cycling capacities of the first 20 cycles of each samples and it was found that LiTf and LiTFSI salts offer the best cycling behavior in this system. Although the salts appear to effect the cycling behavior, the decomposition of the solvent has a larger impact on the cell cycling [27].

\subsubsection{Air Electrode}

The air electrode in lithium oxygen batteries must be designed with certain aspects to facilitate the reactions. It needs to be an electrically conductible, high surface area and chemically stable porous membrane that allows fast oxygen diffusion to the reaction sites. Different materials, such as porous gold or various morphologies of carbon, have been investigated to provide those capabilities [33,34]. Although porous gold has recently been demonstrated to have better reversibility, carbon material has been the most research material in lithium oxygen batteries for its low cost and high surface area. Thus, this study will focus on the carbon-based cathode to better understand the reaction. Composed of a carbon element and a polymer binder, the material composition of the air electrode has attracted a lot of attention in the early development of $\mathrm{Li}_{-} \mathrm{O}_{2}$ cells. The specific properties of the different carbon material have shown to be the most important 
factor in the initial capacity density of the batteries. With extensive progress in that direction, the cyclability of the cells while maintaining a high capacity has lately been of interest and stability of the electrolyte has been the focus in the last five years [27].

A collection of carbon materials have already been investigated for their first discharge capacity and the number of cycles at which they retain an acceptable capacity. Super $\mathrm{P}^{\circledR}$, Ketjen Black, Graphites, Carbon NanoTubes or active coal have been explored under different conditions assessing their performance $[5,35]$. Other types of carbon have also been studied and demonstrated in the literature, such as Shawinigan Black acetylene black or Black Pearls 2000 though their inferior performance has excluded them as plausible candidate [36].

Although it is obvious that decomposition of the electrolyte has a large effect on the overall reversibility of lithium-air batteries, the effect of the carbon material on the electrolyte is a topic that has just recently been revisited in the literature. A common observation from the early investigations of the various carbon materials suggests that high surface area carbons - such as KentjenBlack - have a higher first discharge capacity than a low surface area carbon - such as graphite or carbon nanotubes. However, the capacity of high surface area carbons with high pore volume often fades away much faster than other low surface area carbon $[37,38]$. Thus, with efforts to prolong the initial capacity throughout the life of the battery, low surface area with low pore volume carbons are becoming attractive alternatives that would fulfill the goal of a stable system.

\subsubsection{Limitations}

The lithium-oxygen battery has great potential to revolutionize the way energy is stored; however, the technology is far from commercialization. The state-of-the-art have demonstrated lithium-oxygen batteries on an experimental and practical level [39] but none have shown practical lifespan. The reactivity of the reaction benefit the system by providing high energy density but also hinders the technology by not being stable. The oxygen evolution reaction (OER) generates corrosive species that affect the stability of the electrolyte and cathode material. Furthermore, side reactions can occur and form carbonate and hydroxide groups that cannot be easily cycled. For that reason, carbonate-based electrolytes were found to be unsuitable for lithium-oxygen batteries. The cathode material has also been discussed to promote the formation of carbonates. Many researches have concluded that carbon-based cathodes are relatively unstable and that an alternative material is required to obtain a reversible system [15, 25, 33, 34]. Five considerations were suggested to better understand the reaction mechanisms and to advance the technology [40]:

1) The chemistry is highly reactive and may never be completely reversible. However, a sufficiently stable system (little decomposition of electrolyte) is desirable.

2) Understanding the nature of the degradation products is quite important. Slight progress on the cyclability capability will not help improve the technology if the side reactions are not understood.

3) Carbon may not be the appropriate cathode material as carbonate species evolve. Lithium carbonate is not promoted in gold-based electrodes. 
4) Catalysts should not be explored at this current state of the technology because it will not prevent the side reactions to occur. However, a mediator that reduces the impedance of lithium peroxide can drastically improve the overall reaction and the cyclability of the cells.

5) Finally, the last approach to advance $\mathrm{Li}-\mathrm{O}_{2}$ cell chemistry that should be pursued is the $\mathrm{CO}_{2}$ and $\mathrm{H}_{2} \mathrm{O}$ tolerance with this chemistry as obtaining a very high purity of oxygen supply will be a challenge in a realistic system.

\subsection{SCOPE OF WORK}

This work focuses on understanding the nature of degradation of products in lithium oxygen batteries. More specifically, on the characterization of the discharge product, lithium peroxide, to further understand the reaction mechanisms as a function of the carbon structure used in the air cathode. The properties of the carbon material used in lithium oxygen batteries have shown to affect the specific capacity of the battery [35]. The relationship between the capacity as well as the voltage profile of the battery is investigated, and the amount of discharge products in the battery cell in terms of the carbon material is assessed. A range of carbon properties (surface area and pore volume) are tested in identical testing conditions.

Three techniques will be utilized to help achieve this goal: galvanostatic cycling, $\mathrm{Li}_{2} \mathrm{O}_{2}$ titration and electrochemical impedance spectroscopy (EIS). The titration technique in conjunction with the galvanostatic cycling will help assess the performance of the chemistry with different carbons and EIS will provide insights on the impedance evolution of the discharge products.

Prior to conducting this fundamental study, a laboratory station had to be established at the Oregon Tech Wilsonville campus. A significant amount work was allocated in setting up the equipment to validate any work pursued in the laboratory. 


\subsection{EXPERIMENTAL SETUP}

A tangible outcome from the presented work is the establishment of a versatile laboratory station at Oregon Tech Wilsonville campus. New equipment was acquired for direct use in this project. The recent relocation to new campus facilities required laboratory equipment to be re-calibrated and outfitted to the current need. Thus, this chapter discusses the design decisions made to establish the battery research laboratory station. Although the presented work is focused on the lithium-oxygen cells, the laboratory station was set up to accommodate various types of batteries, fuel-cells or capacitor research.

\subsection{CATHODE PREPARATION INSTRUMENTS}

In battery fundamental research and more specifically in lithium-oxygen cells, a large amount of work goes in the preparation of electrode materials (cathode in the case of $\mathrm{Li}-\mathrm{O}_{2}$ ). Commonly, a slurry of active material is created and applied to a substrate layer that may act as a current collector. Once dried, the final product can be used to be assembled in a cell. As one may expect, the material composition as well as the process in combining them has a crucial effect on the performance of the sample when tested.

To prepare a porous carbon cathode, the carbon material is crushed into a fine powder and mixed with the binder and solvent using a homogenizer. Once mixed, it is common to have slurry buildup on the sides of the vial in which it was mixed. This can affect the homogeneity of the slurry. By putting the vial in an ultrasonic bath, the buildup will settle back at the bottom of the vial. After layering the slurry onto a substrate, the cathode is ready to be placed in a vacuum oven where any moisture is removed from it. The composition of the various slurries and the methodology is discussed in Chapter 3, as this section highlights the capabilities of the instruments used.

\subsubsection{Homogenizer}

In the slurry preparation for cathodes, a thorough mixing of the materials is crucial to create a homogeneous solution. Three compounds with specific purposes are required to make lithiumoxygen cathode slurries: an active carbon, a binder and a wetting agent. A highly volatile carbon powder is combined with a binder to appropriately create a stable membrane that can withhold various chemical and physical conditions. The use of a wetting agent in the process allows a more thorough homogeneity on the nano-scale though it is evaporated before utilizing the electrode. Although more homogenous solution is acquired with a low viscosity slurry, the deposited layer on the electrode has less desirable mechanical properties once dried. The used of high speed mixer can acquire the homogeneity required with high viscosity solutions.

A laboratory grade homogenizer is specifically designed to provide high-energy mixing that is capable of creating a relatively uniform paste. Designed to operate between 500 and 25,000 rpm, the equipment is engineered to mix viscous solution that other instruments would not be able to 
(i.e. stir bar). Figure 2.1.1 illustrates a commercial homogenizer capable of mixing at speeds up to $24,000 \mathrm{rpm}$.

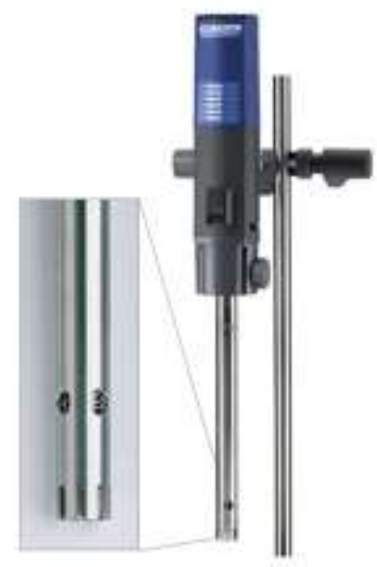

Figure 2.1: IKA T-18 Basic Homogenizer commercially available from Cole Parmer.

By reverse-engineering this laboratory grade instrument, an alternative was found to achieve similar capabilities for a $10^{\text {th }}$ of its cost. A variable speed Dremel operating between 5,000 rpm to 25,000 rpm provided the correct framework to a custom laboratory tool. A mixing bit was manufactured with a $1 / 8$ in. diameter stainless steel (SS) rod to match the same design as the internal rotating bit from the homogenizer (Figure 2.2, right). The static outer tube found on the homogenizer was manufactured out of a 1/4 SS tube and a 3/8 hole was drilled through the side to provide a powerful fluid mechanics flow. However, securing the static outer tube in a perfectly aligned manner was found to be challenging and the contacts between the rotating bit and the tube created undesired particles in the mixture, as seen in the two translucent samples in Figure 2.3. Thus, the outfitted Dremel was tested with the rotating bit alone and adequate results were found in relatively lower viscosity solutions. For ease of use, the Dremel homogenizer was secured to a stand as shown in Figure 2.3, left. Additionally, a hot plate was placed underneath to provide heating capabilities - which reduces the solution viscosity.
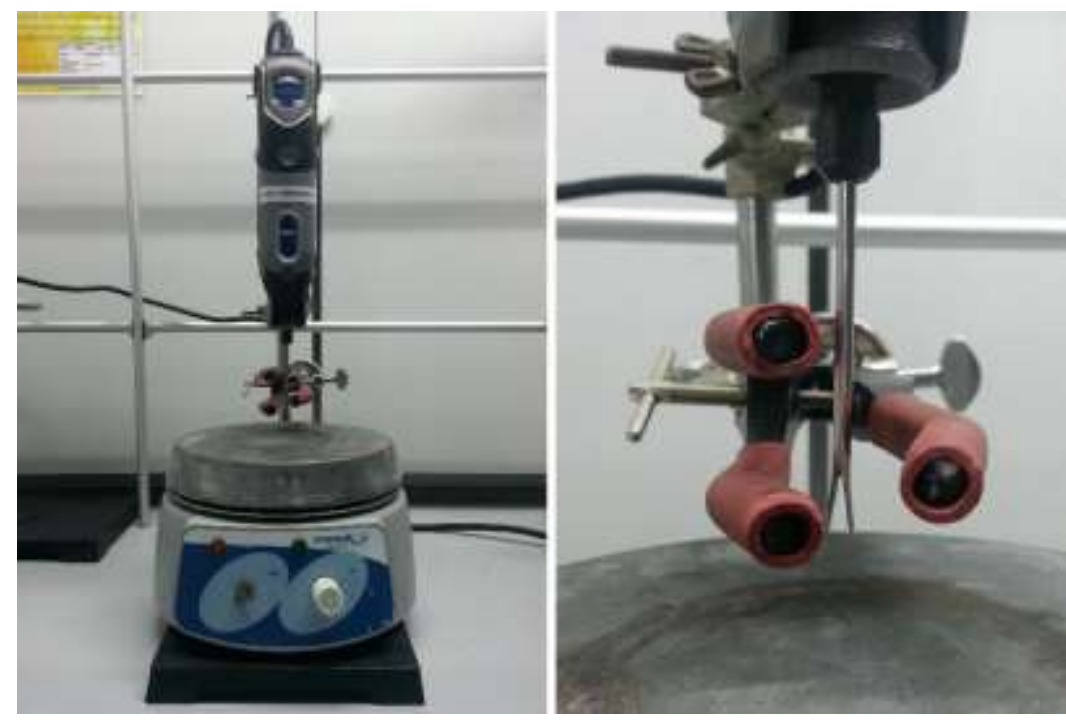

Figure 2.2: Custom Homogenizer. Outfitted Dremel on its stand (left). 1/8th SS mixing bit (right). 


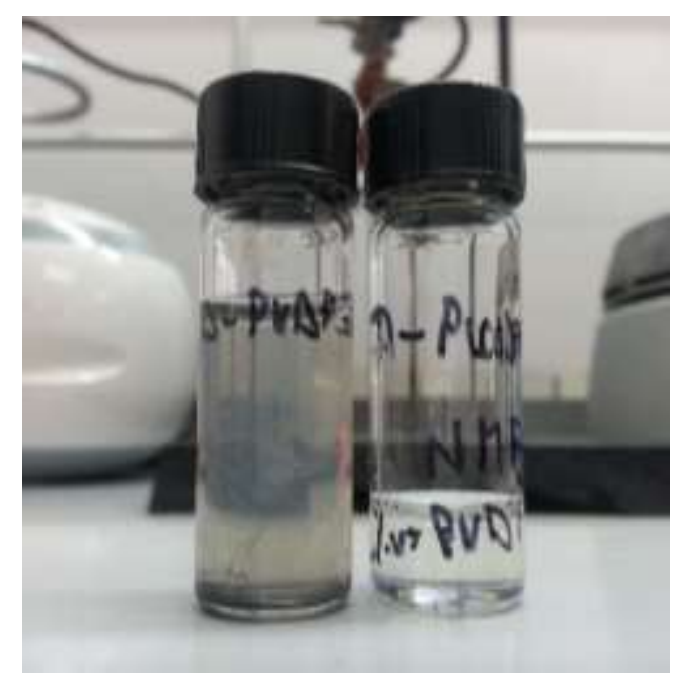

Figure 2.3: Binder solutions showing the introduction of impurities when a 1/4" SS guard was used.

\subsubsection{Ultrasonic bath}

The purpose of an ultrasonic bath (colloquially known as sonicator) in the cathode preparation is to reduce the accumulation of slurry on the walls of a vial that could potentially alter its concentration. The instrument exposes the sample in a distilled water bath to vibrations over 20 $\mathrm{kHz}$. This settles any build-ups and insures that the entirety of the slurry composition is homogenously mixed. A jewelry cleaner was found to provide similar capabilities to a laboratory-grade sonicator, as shown in Figure 2.4.

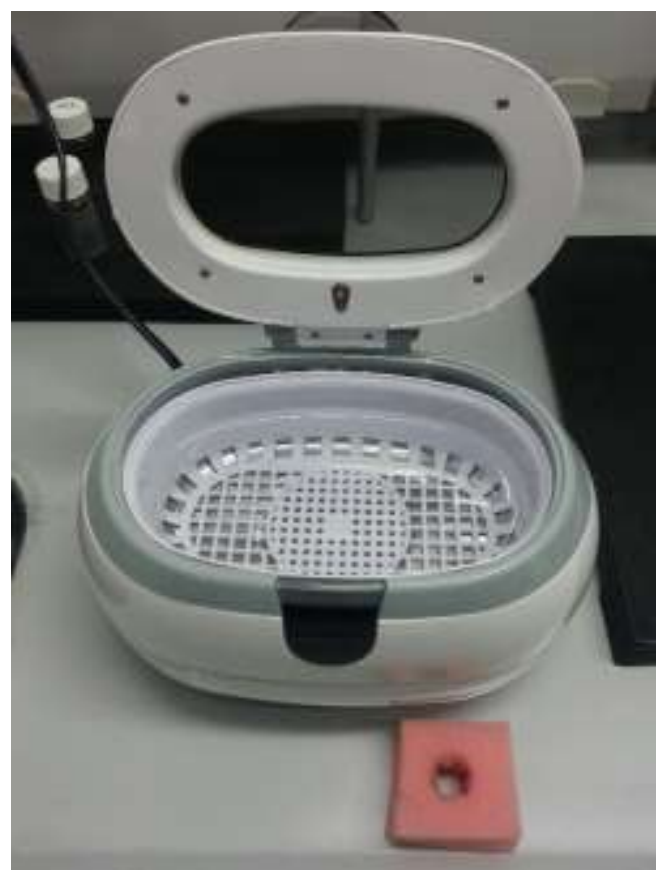

Figure 2.4: Ultrasonic Bath. 


\subsubsection{Vacuum oven}

The last equipment addition discussed in the cathode preparation sub-section is a laboratory grade vacuum oven. As the presence of moisture has a drastic negative effect in lithium oxygen cells, the combination of heat and low pressure allows to virtually remove any moisture from electrodes and other components of the cells. A Shel Lab SVAC1 vacuum oven connected to a stand-alone rotary vacuum pump (Figure 2.5) allows to dry electrode at vacuum levels of -29.8 inHg and at $200{ }^{\circ} \mathrm{C}$. Additionally, the oven was connected to high purity argon $(99.998 \%)$ gas to reduce the exposition of electrodes to moisture when transferred to the glove box.

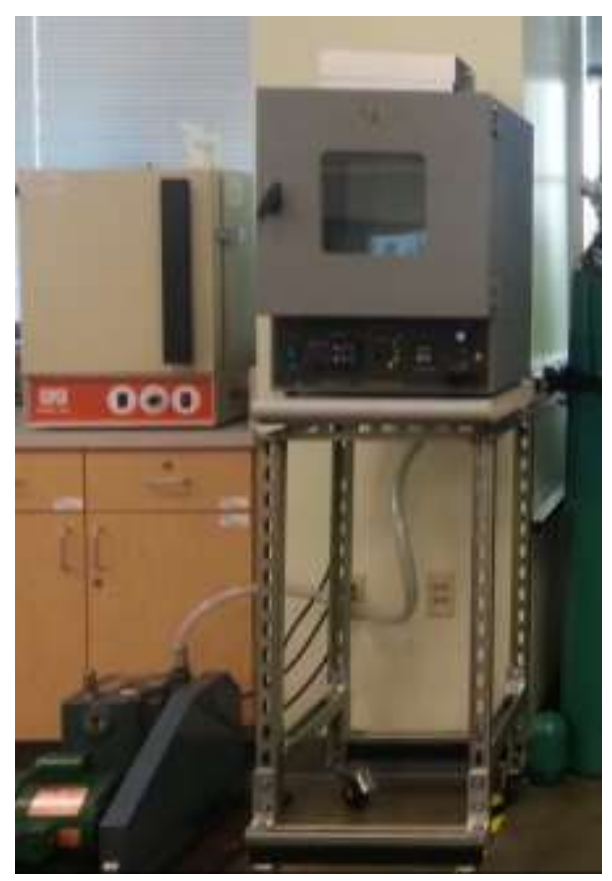

Figure 2.5: Vacuum Oven for electrode drying.

\subsection{CONTROLLED ENVIRONMENT CHAMBER}

Due to the nature of this research, a controlled environment chamber was established to reduce the decomposition of the materials as well as protect specific chemicals from moisture and oxygen. Storing metallic lithium as well as anhydrous electrolytes in an inert environment has provided longevity to the chemicals as well as enhanced laboratory safety. To serve that purpose, the VGB-3 MTI glove box - previously acquired by the university - was put in proper working condition. The initial approach of contacting the manufacturer to acquire documentation on the VGB3 was unsuccessful as MTI has not been recently retailing this system. Furthermore, the company was not able to provide any user manuals or specification sheets on the VGB3 glove box. Thus, this sub-section discusses the design decisions that led to a fully working system. 


\subsubsection{Custom Gas Connection}

The foremost design made on the glove box is the gas flow layout. Highlighting simplicity and practicality, the gas connection is based on multiple commercial design from various manufacturers (MBraun, Inc, Innovative Technology, Inc., ...). As state-of-the-art commercial system features a purification system that continuously recirculate and purify the inert gas, this glove box system is designed to operate more closely to a purge box (system requiring significant purging to maintain adequate levels of purity). Thus, the gas connections were designed to maximize the use of the gas while still maintaining this high level of purity.

The layout is designed to take advantage of the working pressures of the working and transfer chambers as well as the working pressure of the gas supply, as shown in Figure 2.6. By design, the working chamber pressure is set slightly higher than the atmosphere to encourage leakage outwards. Also by design, the transfer chamber is placed under vacuum to maintain a good seal on the isolating doors. Finally, the gas supply is set to be three times the working chamber pressure to be able to provide enough back pressure in the case of a large leak. Therefore, the gas flow is designed to flow from the gas supply to the working chamber and finally to the transfer chamber. A vacuum pump is used to maintain a low absolute pressure inside the transfer chamber outputting the inert gas to the atmosphere.

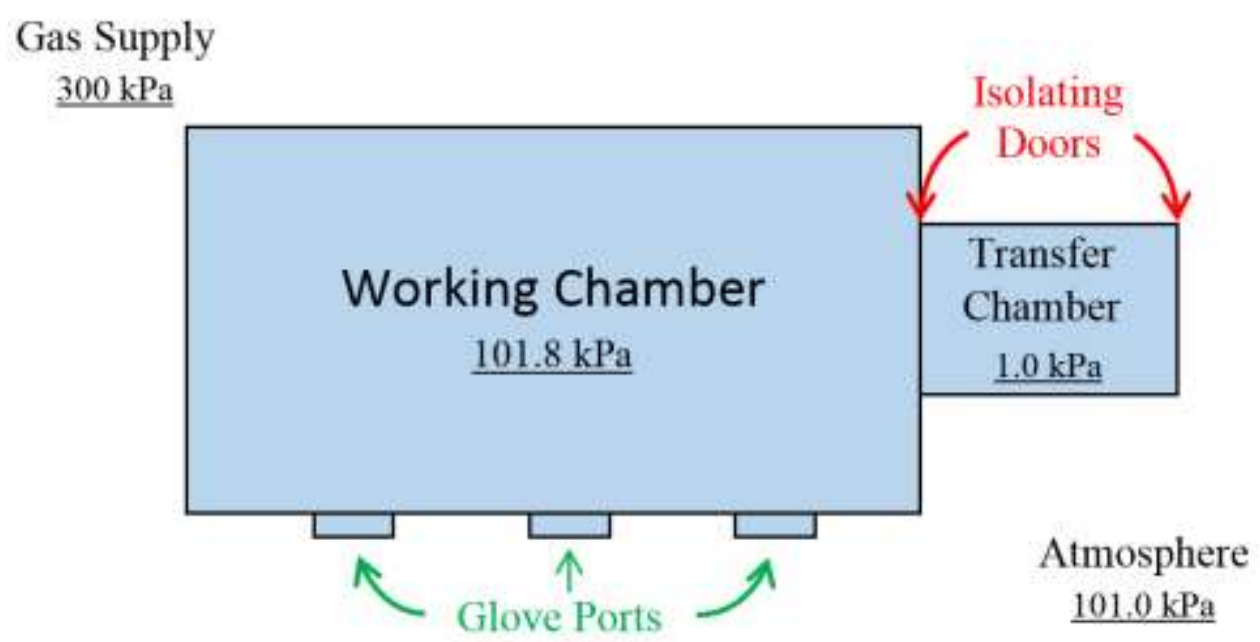

Figure 2.6: Simplified glove box layout with working pressures.

To maintain a positive pressure in the working chamber, an automatic pressure controller (EQKJT-2V, MTI) packaged from MTI is placed in line with the gas flow. A pressure transducer (TG22-08, STNC Inc.) is used to measure the pressure inside the working chamber with $0.1 \mathrm{kPa}$ accuracy. The feedback is sent to a controller (AL-501, Yudian Automation) that operates two solenoid valves placed on the gas supply and between the working chamber and the transfer chamber. This configuration utilizes the positive pressure of the gas supply and the negative relative pressure of the transfer chamber to maintain the working pressure within a set boundary. The controller can be programmed to operate within a comfortable pressure during use and at 
higher pressure when the system is idle. Furthermore, the controller also features alarms and output channels that can be used in the future to further automatize the gas supply system.

Another key feature of this custom gas flow system is the 2 three-way valves on the gas supply and the transfer chamber. A three-way valve is used for the argon gas supply to allow line purging capabilities without introducing air to the working chamber, as shown in Figure 2.7. As gas tanks need to be periodically changed, it was important to design the connection to be purged before reconnecting it to the glove box. Similarly, a three-way valve is placed between the working chamber and the transfer chamber to manually control the transfer chamber pressure, as shown in Figure 2.8. This valve is placed in parallel with the solenoid valve from the automatic pressure controller to avoid interfering with one another.

All the gas connections are designed with Swagelok compression fittings to reduce the chances of leaks. The connection on the solenoid valves from the automatic pressure controller were replaced with $1 / 4$ " SS tubing compression fitting and a compression fitting adapter was placed inline with the vacuum pump to also provide versatility.

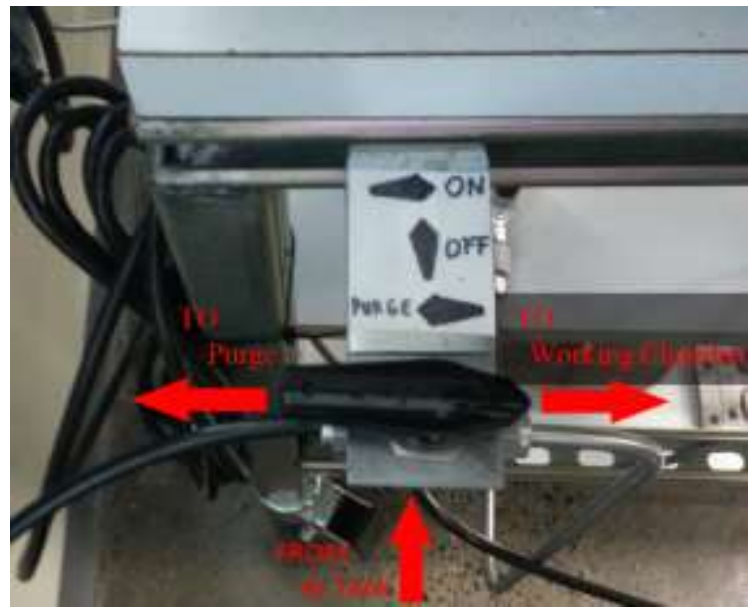

Figure 2.7: Three-way valve used to purge the lines before connecting a new gas tank. Currently allowing flow from the Ar tank to the working chamber.

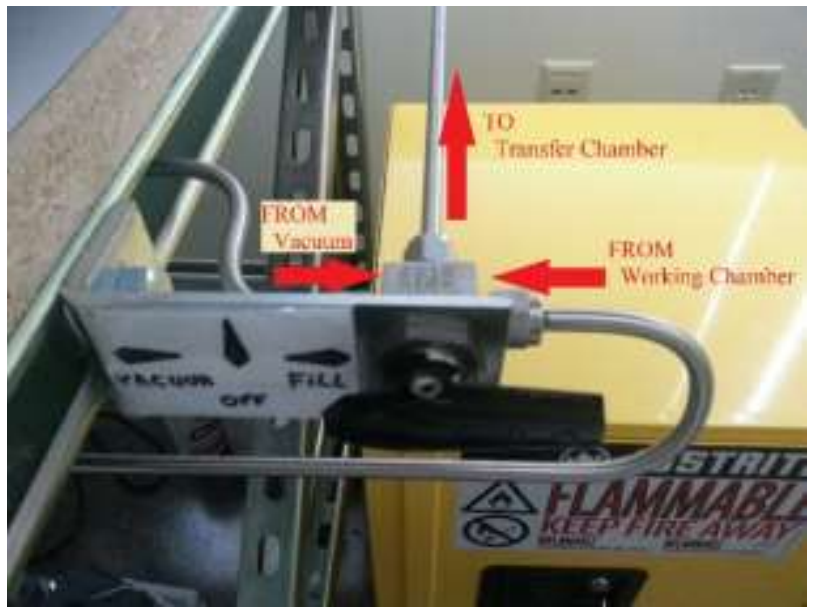

Figure 2.8: Three-way valve used to manually control the transfer chamber pressure. Currently allowing the flow from the vacuum pump to the transfer chamber.

\subsubsection{Gas Monitoring Instruments}

Two instruments were added to the glove box system to monitor the inertness of the environment. An oxygen and a moisture sensor allows to accurately measure the concentrations in the glove box to preserve cell components such as lithium metal, electrolyte, salts or dried cathodes. The addition of these two instruments has been crucial in the operation and condition of the glove box.

An oxygen sensor from Omega Alpha (Series 3000 Trace Oxygen Analyzer) is used to monitor the oxygen concentration within three auto adjusting ranges: $0-100 \mathrm{ppm}(0.01 \%), 0-1,000$ ppm $(0.1 \%)$ and $0-10,000 \mathrm{ppm}(1 \%)$. Based on a similar concept as fuel cells, a constant gas flow passes by a membrane that reacts with the oxygen to generate a current signal. This 
feedback is then used to output a reading on the display. An optional pump was acquired with the instrument to insure the proper gas flow through the sensor. The instrument is a stand-alone system with the capability to be installed externally (1/4" compression fitting). However, the output of the pump was designed with a hose barb that would be fed back to the glove box. To avoid uncertainties with the measurement and reduce the possibilities of leaks, the instrument was located inside the working chamber. In addition, the instrument was placed by the gas outlet furthest away from the fresh gas supply to measure the highest oxygen concentration possible. Alarms with output signals are accessible on the sensor to incorporate the instrument in the automation of the overall glove box.

The second instrument used to monitor the gas purity inside the working chamber is a moisture sensor packaged from MTI (EQ-RH-800). A dew point transmitter (EA2-TX-100, Mitchell Instruments) uses impedance technology to measure the moisture concentration in a gas. A hygroscopic single layer between a permeable gold film and a base electrode has moisture dependent impedance that is characterized to accurately measure moisture. Programmed to measure concentration from 0.1 to $999.0 \mathrm{ppm}$ of moisture, the sensor outputs a 4-20 mA signal that is then read by a controller (AL-501, Yudian Automation). Again, the controller features two sets of alarms and outputs that can be used in the future to automatically control gas supply. The sensor was originally designed to simulate its designed location inside a recirculating system with constant gas flow by being placed in-line between the working chamber and the transfer chamber. It was quickly observed that the high velocity and sporadic gas flow made the moisture reading erratic. Thus, the instrument was placed inside the working chamber and secured next to the gas pump outlet of the oxygen sensor. The estimated gas flow speed by the sensor is slightly lower than the recommended speeds though only the response of the reading is affected by it. Further testing is discussed in the following section.

\subsubsection{System Performance Improvements}

Various design decisions were made to medicate gas leaks and high concentration of oxygen and moisture in the glove box. Although documentation was not available, technicians and engineers at MTI Corp assumed that the VGB3 glove box is not intended for lithium battery research because it was not designed to obtain low moisture and low oxygen concentration. The challenge of making the glove box system as air-tight and as low-diffusion as possible encouraged understanding physical phenomenon on a molecular level (i.e. partial pressures and Venturi effect on a molecular level). Since the working chamber is operated at positive pressure, one may omit the partial pressure of individual gases. As oxygen concentration decrease in the chamber, the pressure difference between the atmosphere and the chamber increases to the point that an absolute oxygen-free chamber will have a 3.09 psi gradient with the outside. Thus, diffusion as well as a Venturi effect of small leaks will have the tendency to increase the oxygen in the working chamber.

The most obvious leak-prone component of the system is the set of flexible gloves. The original set of gloves that were installed on the glove box was made out of natural rubber. However, this material is not recommended for high gas impermeability and not compatible with certain chemicals [42]. Thus, a set of butyl ambidextrous extra-long gloves - the industry standard material - was installed on the three front glove ports to reduce the gas ingress. Additionally, butyl gaskets were placed on the three back glove ports for the same purpose. These additions 
showed drastic improvements on reducing leaks in the system when pressure was observed to be maintained overnight at the maximum gauge pressure $(15 \mathrm{mbar}$ or $1.5 \mathrm{kPa})$. Consequently, the rate of constant oxygen concentration increase associated with partial pressures was reduced from $>10 \mathrm{ppm} / \mathrm{hr}$ to below $1.5 \mathrm{ppm} / \mathrm{hr}$.

After witnessing a relatively high moisture concentration inside the glove box that was only reduced with a large quantity of purging gas ( $3 \mathrm{X}$ the volume of the glove box), an active desiccant filter was designed to capture the moisture present in the environment. Commercially available glove box recirculation system has a minimum cost of $\$ 10,000$ featuring active moisture and oxygen purification systems. With the glove box system present on campus, it was found that oxygen concentration has been able to be brought down to acceptable ppm level by purging with high purity argon gas. However, this method was found to be ineffective with the moisture present inside the system.

The first approach to resolve this concern was to leave a layer of molecular sieve exposed in the glove box for an extended period of time. However, very minimal changes in moisture concentration were observed. Thus, the next approach to the problem was to design an active moisture purification system that would provide a steady flow through a bed of desiccant. A simple sheet metal tower was constructed around a computer fan that would actively circulate the gases through a filter system. A $12 \mathrm{~V}, 0.25$ A computer fan provided the correct flow rate and size needed for the project. The final solution to this issue, as shown in Figure 2.9, illustrates a simplistic, small and ingenious moisture purification system that can reduce the moisture concentration down to acceptable levels.

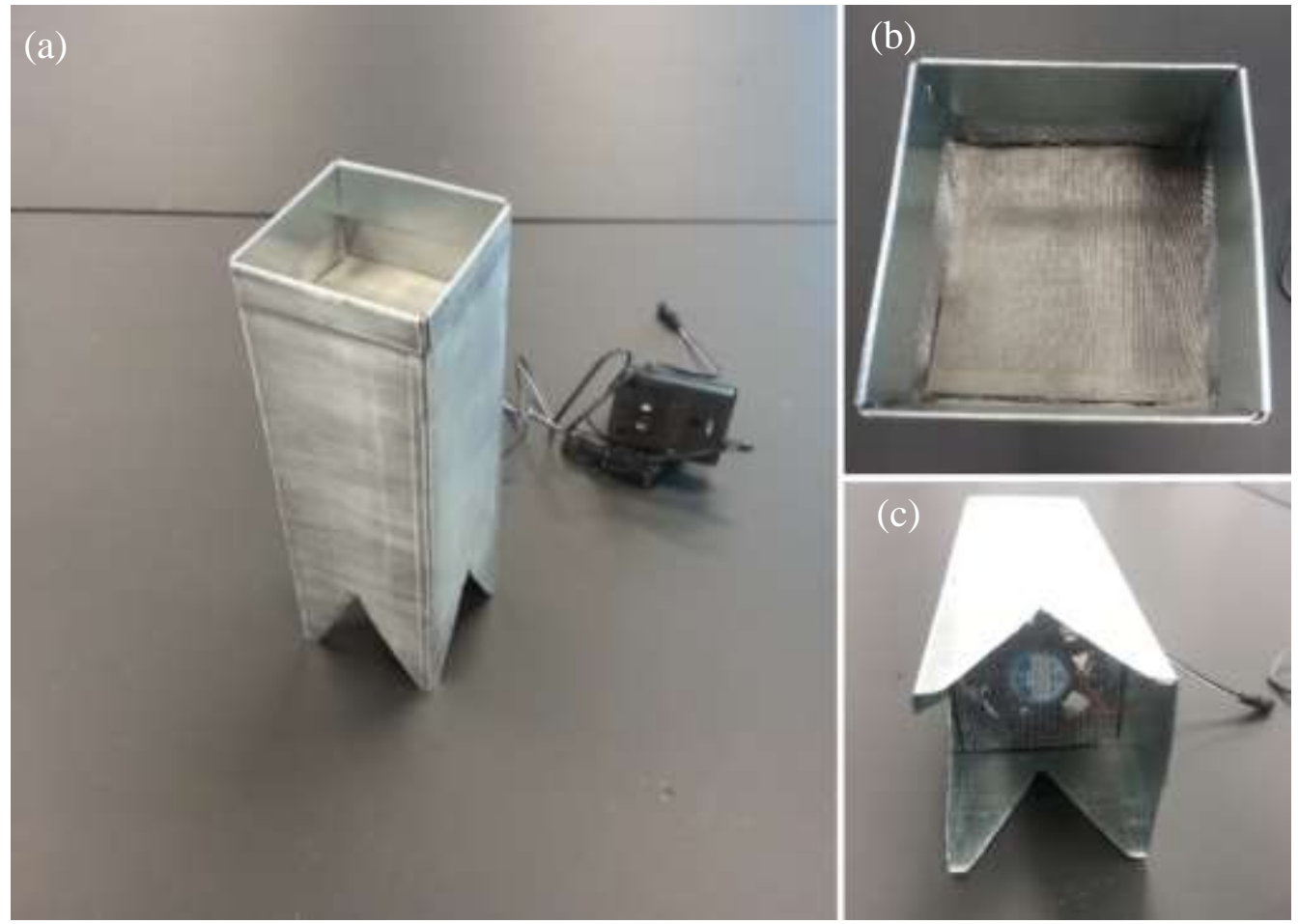

Figure 2.9: (a) Custom Moisture Filter System for the glove box. (b) Metal mesh to contain the desiccant material. (c) $3 \mathrm{~W}$ computer fan. 
The moisture concentration immediately dropped down from $900 \mathrm{ppm}_{\mathrm{v}}$ to $350 \mathrm{ppm}_{\mathrm{v}}$ in one hour and the weight of the desiccant used increased after 40 hours by 5\%. The choice of desiccant material was made on a financial and design requirement basis. The common house-hold desiccant material was investigated for this system, though its inertness in the environmental chamber was questioned. Thus, the use of molecular sieves ( $4 \AA$ ) was found to be the most appropriate desiccant. Furthermore, the benefit of molecular sieves is that they can be regenerated at high temperatures, making a virtually endless supply.

Another physical phenomenon that was sought after and resolved is the molecular weight of oxygen versus argon. The atomic weight of oxygen and argon gases are $32 \mathrm{~g} / \mathrm{mol}$ and $40 \mathrm{~g} / \mathrm{mol}$, respectively. Thus, it was important to design the argon gas inlet to be located as high as possible inside the glove box to circulate the impurities in the glove box. An internal tube was placed to direct incoming gas to a higher location (Figure 2.10).

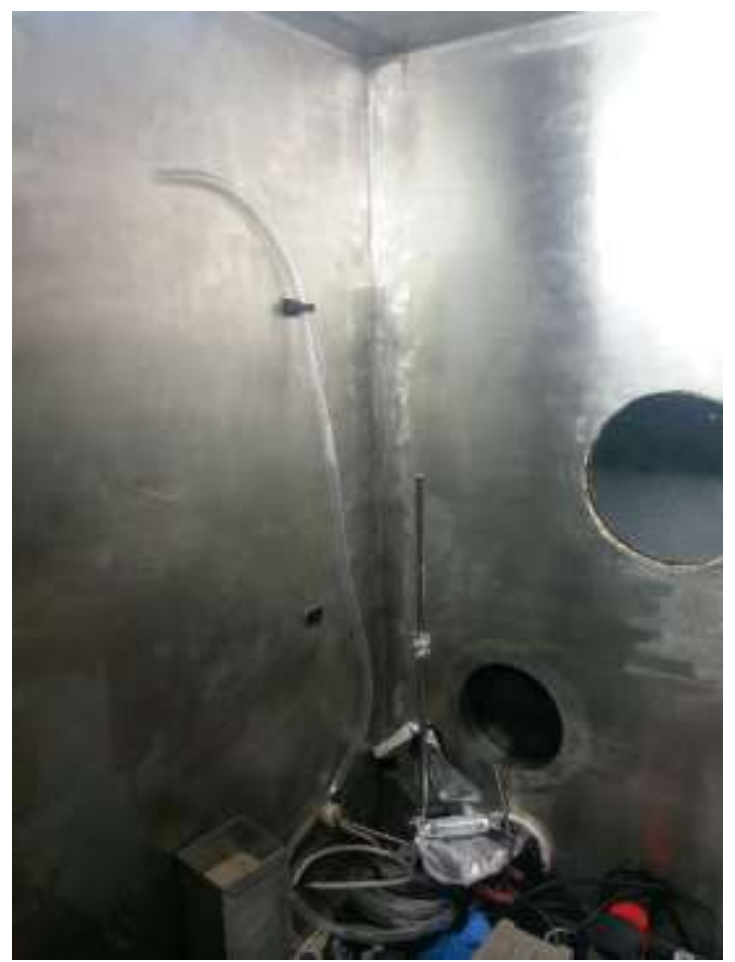

Figure 2.10: Incoming gas redirection.

\subsubsection{Operational Glove box System}

To conclude, the controlled environment chamber achieved higher performance level than originally expected. Oxygen concentration has been observed as low as $40 \mathrm{ppm}$ without extensive purging. Moisture concentration has been maintained below $15 \mathrm{ppm}$, and as low as 7.8 ppm with the desiccant filter. Gas consumption during active research has been on average 300 cubic feet every three weeks which is remarkable when no commercial purification system is used. 
A scale as well as a cutting board has been added inside the glove box for battery assembling purposes. The Sartorius analytical lab balance (Practum124-1S, Sartorius) has both a readability and reproducibility of $0.1 \mathrm{mg}$.

Lastly, a light fixture was designed to provide adequate lighting inside the glove box. A simple folded sheet of metal is used to support an incandescent light without the use of any screws. A simple hook-cantilever combination allows the light to be suspended over the front glass of the glove box, as shown in Figure 2.11.

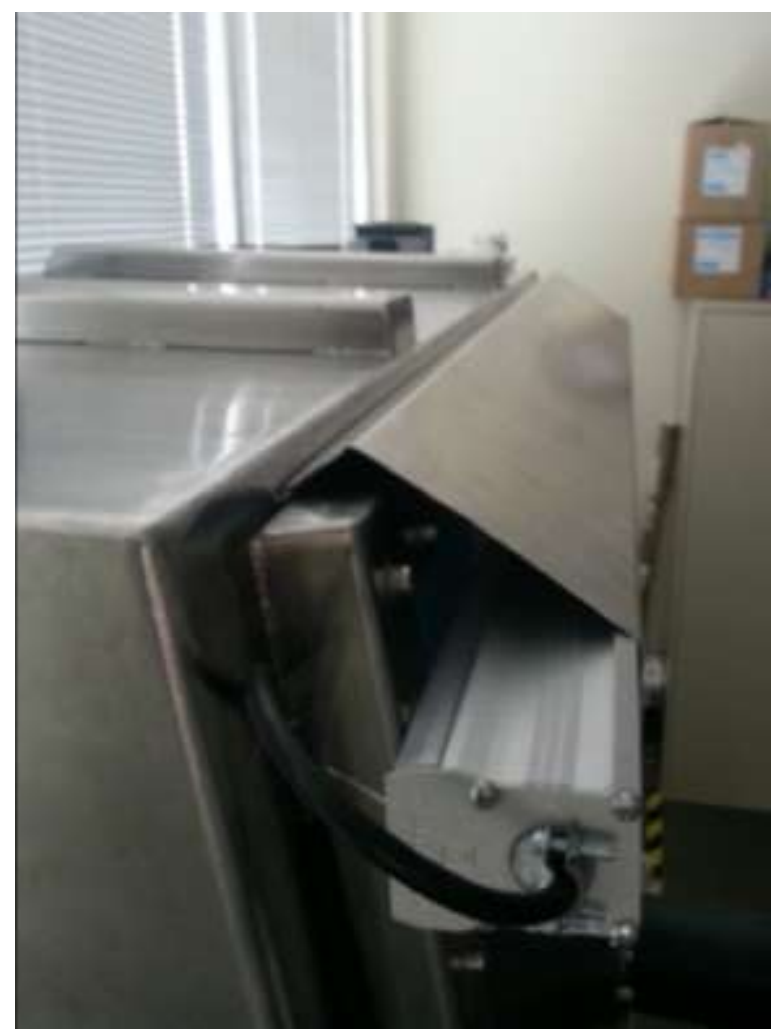

Figure 2.11: Light fixture for the glove box.

\subsection{BATTERY CYCLING STATION}

An 8-channel battery tester (CT2001A5V5mA, Landt Instrument) was used to cycle the batteries. To provide an ultra-high purity (UHP, 99.999\%, Airgas) oxygen supply to each cell, an oxygen supply system was custom-designed for that purpose.

A computer server racking frame was used to secure the oxygen supply system to the Landt Instrument battery tester. Holes in an aluminum bar helped attach each valve to the frame thus reducing torque on the fittings. To hold the cells upright, a broom holder was adapted to clamp each cell under their oxygen supply. A heat shrink used for electrical wiring was placed on each branch of the metal clamp to further reduce the chance of shorting the cell and also to reduce the damage cause when changing cells. An acrylic sheet was placed on top of the Landt Instrument 
to electrically insulate it from the cell and protect the instrument from any accidental leak from the cells (Figure 2.12)

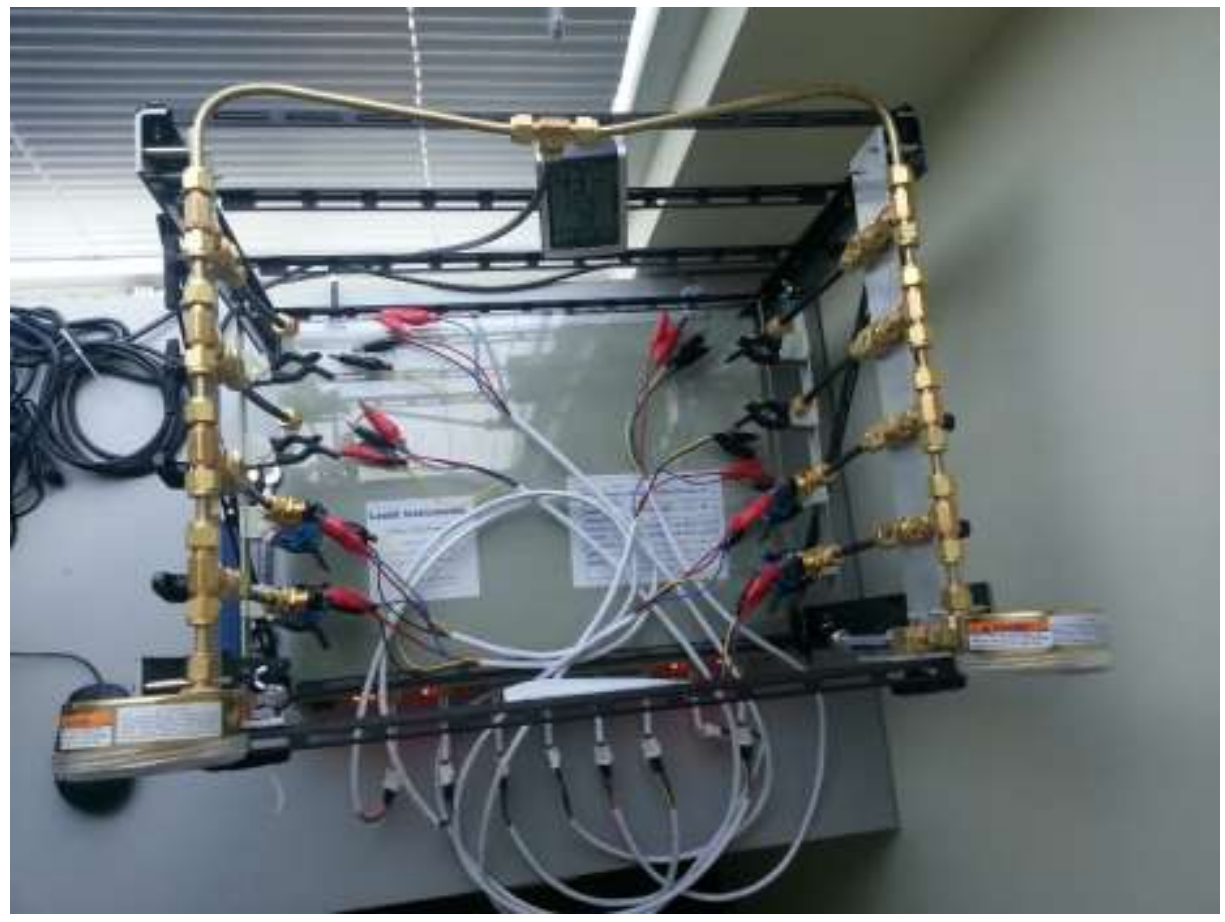

Figure 2.12: Top view of the oxygen supply system. 


\subsection{EXPERIMENTAL WORK}

This chapter discusses the experimental procedures used to conduct the proposed work in section 1.4. The sample preparation section covers the steps taken to prepare the electrolyte, the carbon cathode, the assembling process and the procedure to introduce oxygen. This section also comprises the material and the suppliers that were used for the study. The following sections describe the techniques applied to characterize the samples. Galvanostatic cycling was used to assess the performance of the batteries; titration was used to determine the lithium peroxide yield; and electrochemical impedance spectroscopy helped assess the impedance evolution.

\subsection{SAMPLE PREPARATION}

The key components in a lithium cells are the lithium metal anode, the electrolyte (salts in a solvent) and the air cathode (carbon/binder mix on a substrate). This section discusses the procedure used to prepare each of those components with chemicals commercially available.

\subsubsection{Electrolyte preparation}

Tetraethylene glycol dimethyl ether (Tetraglyme/TEGDME/4G, 99.91\%, BASF Corporation) essay had a water content of $88 \mathrm{ppm}$ and was dried with molecular sieves (4 $\AA$ ) for a week in the glove box. Dimethoxyethane (monoglyme/DME/1G, anhydrous, $99.5 \%$, Sigma Aldrich) was used as received. Dimethyl carbonate (DMC, $99.5 \%$, Sigma Aldrich) was dried with molecular sieves ( $4 \AA$ ) for a week in the glove box. Lithium trifluoromethanesulfonate (LiTf, 99.995\%, Sigma Aldrich) was dried in a vacuum oven at $80{ }^{\circ} \mathrm{C}$ for 48 hours before bringing it inside the glove box. Bis(trifluoromethane) sulfonamide lithium salt (LiTFSI, 99.95\%, Sigma Aldrich) was used as received since it was packaged in an inert environment. Each of these chemicals were stored in the glove box permanently with moisture concentration below $10 \mathrm{ppm}$.

The electrolyte solution was prepared by actively mixing salts into the specific solvent and was left overnight to insure complete dissolution. The concentration of each electrolyte solution was established with the molecular weight of the salt $(156.0 \mathrm{~mol} / \mathrm{g}$ for LiTf $)$ and the specific density of the solvent $(1,009 \mathrm{~g} / \mathrm{L}$ for tetraglyme).

Unused lithium metal was placed in the electrolyte to further react with any moisture and preserve the salt concentration of solution. Each solution was permanently stored in the glovebox.

\subsubsection{Air Electrode Preparation}

Five variations in the air cathode materials were tested in this study. The carbons were combined with a binder solution to deposit them onto a carbon paper substrate. The solvent used to mix the binder and carbon is then evaporated before using the cathode. 
Ketjen Back, KB (EC-600JD, Akzo Nobel Polymer Chemicals) carbon was crushed with a pestle and mortar for 20 minutes to obtain a fine power. Acetylene Black, AB (AB 50\%-01, Soltex Synthetic Oils \& Lubricants of Texas, Inc.) carbon, Volcan Black, XC72 (CV-XC72R, Clean Fuel Cells Energy, LLC) carbon, multi-walled carbon nanotubes, CNT (MCNT 8-15 nm, Cheap Tubes Inc.) and graphene nanoplatelets, Graph. (Grade 4 GNPs, Cheap Tubes Inc.) were used as received. The properties of each carbon as reported by the manufacturer can be found in Table 3.1.

Table 3.1: Properties of carbon materials studied.

\begin{tabular}{l|l|c|c}
\hline Carbon & Morphology & Surface Area $\left(\mathbf{m}^{2} / \mathbf{g}\right)$ & Pore Volume $\left(\mathbf{c m}^{3} / \mathbf{g}\right)$ \\
\hline Graphene Nanoplatelets (Graph.) & Planar & 750 & 0 \\
\hline Multi-walled Carbon Nanotubes (CNT) & Tubular & 233 & 0 \\
\hline Volcan XC 72 (XC72) & Spongious & $235^{*}$ & $0.32^{*}$ \\
\hline Ketjen Black (KB) & Spongious & 1,400 & 7.6 \\
\hline Acetylene Black (AB) & Spongious & 75 & $0.23^{\#}$ \\
\hline
\end{tabular}

* Properties not available from the manufacturer [43]

\# Property not available from the manufacturer [44, 45]

A binder solution was prepared by mixing $3 \mathrm{wt} \%$ polyvinylidene fluoride, PVDF binder (Kyna 900, Arkema Inc.) and 1-methyl-2-pyrrolidinone, NMP solvent (Anhydrous, $99.5 \%$, Sigma Aldrich) with the homogenizer at elevated temperature $\left(\sim 80^{\circ} \mathrm{C}\right)$ until it fully dissolved. The solution was cooled down to room temperature before use. To mix the slurry, each carbon was added to the binder solution with a 4:1 weight ratio and additional NMP solvent included in the solution to acquire proper wetness. Table 3.2 recapitulates the proportion used for each carbon.

Table 3.2: Optimized mixing ratios for carbon electrode slurries.

\begin{tabular}{l|c|c|c}
\hline \multicolumn{1}{c|}{ Carbon Material } & Binder Solution & Carbon & Additional NMP \\
\hline Graphene Nanoplatelets & $0.667 \mathrm{~g}$ & $0.080 \mathrm{~g}$ & $0.0 \mathrm{~g}$ \\
\hline $\begin{array}{l}\text { Multi-walled Carbon } \\
\text { Nanotubes }\end{array}$ & $0.667 \mathrm{~g}$ & $0.080 \mathrm{~g}$ & $0.650 \mathrm{~g}$ \\
\hline Volcan XC 72 & $0.667 \mathrm{~g}$ & $0.080 \mathrm{~g}$ & $0.800 \mathrm{~g}$ \\
\hline Ketjen Black & $0.667 \mathrm{~g}$ & $0.080 \mathrm{~g}$ & $1.765 \mathrm{~g}$ \\
\hline Acetylene Black & $0.667 \mathrm{~g}$ & $0.080 \mathrm{~g}$ & $0.500 \mathrm{~g}$ \\
\hline
\end{tabular}

The slurries were spread with a SS spatula on carbon paper (Toray TGP-H-030, Fuel Cells Etc) and dried at room temperature for at least 48 hours in a covered petri dish to slow the evaporation. This process showed improved concentration of cracks found on the electrodes. The same slurry was used in multiple occasions sometimes over a few weeks after it was made and it was found that the drier the slurry was, the fewer cracks were found at higher loading. Due to the accuracy of the analytical balance, the loading of the electrodes were on average $2 \mathrm{mg} / \mathrm{cm}^{2}$. The electrodes were punched with a 1/2" O'Brien Arch Punch (PerfectFit) outside the glove box and dried for at least 36 hours in a vacuum oven at $70{ }^{\circ} \mathrm{C}$. The oven was then purged with HP argon gas and placed in the transfer chamber of the glove box where a deep dynamic vacuum was maintained for at least an hour before use. The electrodes were stored in the glove box in separate vials. 


\subsubsection{Cell Assembly}

A slightly adapted Swagelok design was used to house each cell [46]. A stainless steel tubing (1/2" diameter, Swagelok) and rod (89535K15, McMaster-Carr) was inserted on either side of a perfluoroalkoxy, PFA, 1/2" union (PFA-820-6, Swagelok) to provide oxygen access and closure for the cell, respectively. A SS conical compression spring (1692K22, McMaster-Carr) provided pressure on the cells and electrical connection to the SS rod. A 1/2" SS disk (2895T51, McMasterCarr) placed between the spring and the cell provided a distributed even pressure across the battery. The original PFA ferrule sets in lieu of SS were used for the assembly since a good seal was obtained and it still permitted to be adjusted (for appropriate spring compression). A recapitulating figure can be found below (Figure 3.1).

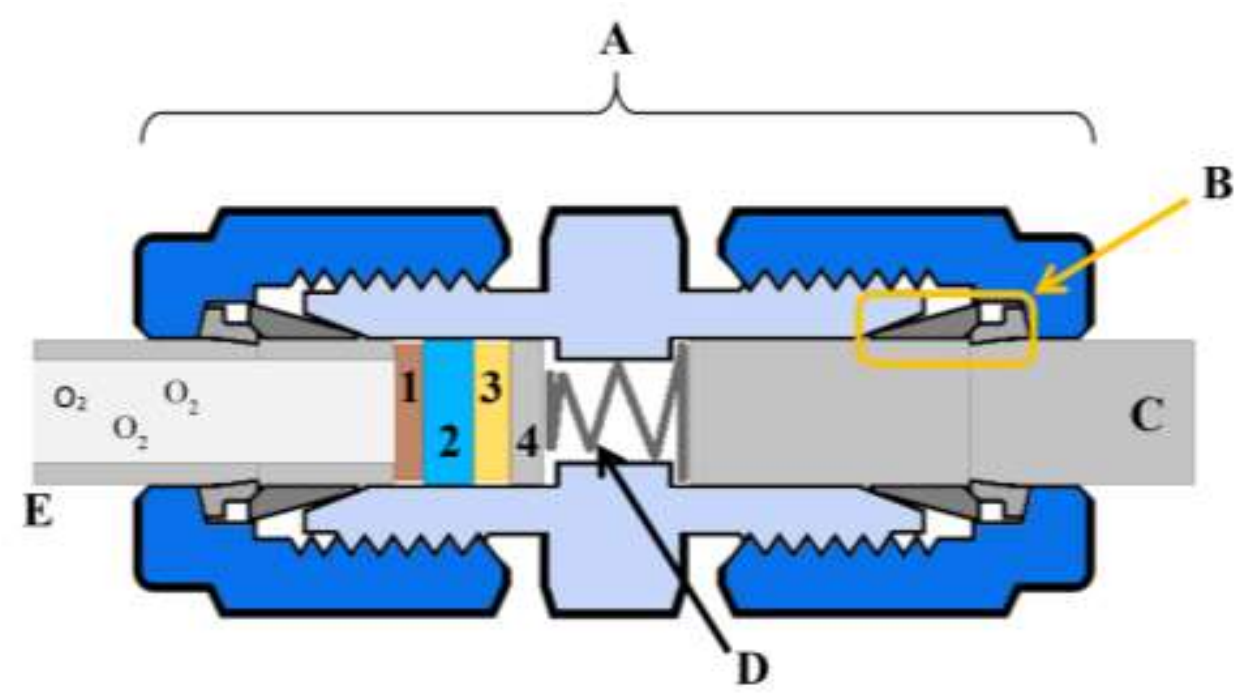

Figure 3.1: Cross-section assembly of a Swagelok cell design. (1- Air cathode, 2- Spacer/electrolyte, 3- Lithium Anode, 4- Stainless Steel Spacer, A- Swagelok PFA Union, B- PFA ferrule set, C- Stainless Steel rod, DStainless Steel Spring, E- Stainless Steel Tubing).

Concerning the electrochemical cell, the anode was a lithium metal foil $(0.6 \mathrm{~mm}$ thick, GoodFellow) punched with a 3/8 arch punch inside the glovebox and used within 2 weeks of being punched. A $1 / 2$ " glass fiber paper (GF/B, Whatman) was used as separator soaked in electrolyte. A $1 / 2$ " polypropylene (PP) membrane (2500, Celgard) was used to prevent adhesion from the cathode on the glass fiber paper. Lastly, the carbon electrode was placed on top of the PP membrane with the carbon paper current collector facing the stainless steel tube. The cell was closed with the other side of the union with a close in-lined valve to isolate the electrochemical cell from the environment. The compression of the spring was kept as consistent as possible by compression the SS rod as far as possible onto the internal lip of the union. The back of the ferrule set on the SS tube was placed at 0.6 inches from the end of the tube.

Once the samples were assembled, they were rested for 2 hours to allow the electrolyte to impregnate everywhere inside the cell wetting all the surfaces of the various carbons. The cells were then taken out of the glove box for testing. The small volume of argon gas trapped between the electrodes and the valve $\left(2.08 \mathrm{~cm}^{3}\right)$ was removed by applying the cell to a shallow vacuum ($25 \mathrm{inHg}$ absolute pressure) and quickly replaced with UHP oxygen gas. At the operating pressure 
of $4 \mathrm{psig}$, the total number of moles of oxygen stored in that volume was $109 \mu$ mol though the valve was never shut off during testing. To attach the alligator clips of the battery tester onto each cell, two hose clamps were tightly secured on the SS rod and SS tube (see Figure 3.2). Lastly, a PFA flexible tubing was used to connect each individual cell to the oxygen supply system while still electrically insulating them from one another (Figure 3.2). The samples were connected vertically with the air cathode facing upward to reduce the loss of electrolyte and to insure its even distribution. Each cell was numbered and associated to a specific channel on the battery tester to avoid over-tightening their compression fitting, as recommended by Swagelok Figure 3.2 shows channel 1 and 2. When connecting a new cell to the oxygen system, the oxygen system valve (top of Figure 3.2) was opened to purge air out of the PFA tubing. The connecting nut was then tightening slowly reducing the leak. Once completely air tight, the valve on the Swagelok cell (bottom of Figure 3.2) was opened exposing the battery to the UHP oxygen gas. When the testing was concluded, the samples were disassembled inside to glove box. For safety reasons, each electrode was placed in their respective waste containers.

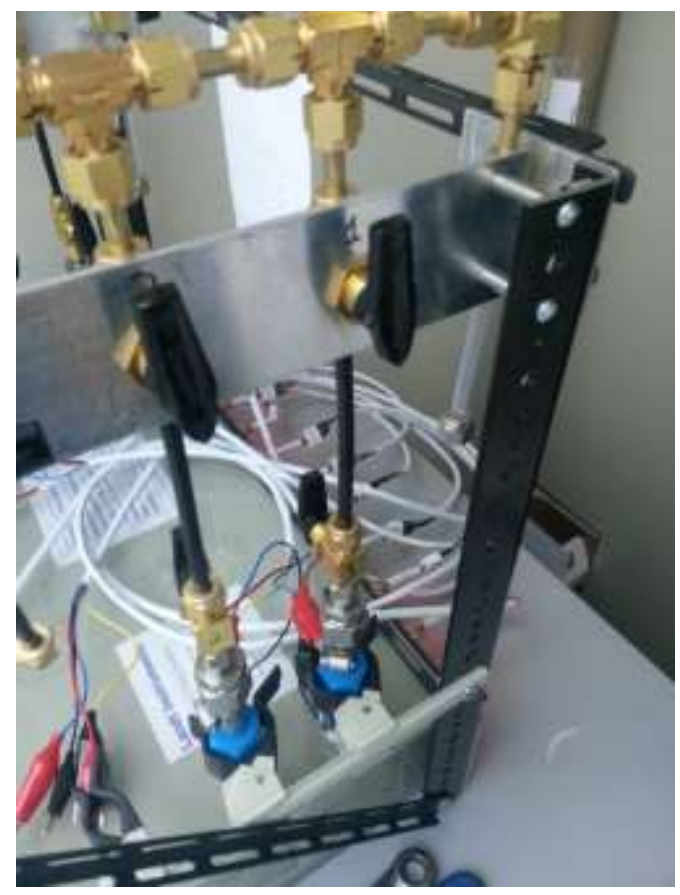

Figure 3.2: Fully Assembled Swagelok Cell connected to the oxygen supply system.

\subsection{GALVANOSTATIC CYCLIC TEST}

The foremost testing technique characterizing the effect of various carbon morphologies in a lithium-oxygen cell is a galvanostatic cyclic test. This repeatable test assesses the overall performance of cell at a specific cycling rate. A constant current (CC) per unit area $\left(\mathrm{mA} / \mathrm{cm}^{2}\right)$ testing condition is used for the discharge and charge cycle as it allows to comparatively analyze the current density of each cell while maintaining constant conditions. This testing condition is displayed differently from how commercial battery cycling rates $(1 \mathrm{C}, 2 \mathrm{C}, 1 / 2 \mathrm{C}, \ldots)$ are denominated as the overall capacity delivered from each sample varies by their composition and design. For instance, the thickness of the electrode will vary the overall capacity and the charge 
transport rate will depend on its area. The galvanostatic cyclic testing outputs a capacitydependent voltage profile that highlights the different reaction potentials.

In the case of $\mathrm{Li}-\mathrm{O}_{2}$ chemistry, a few distinct plateaus (leveled potential as the cell is discharged) in early cycles have been associated to specific chemical reactions. As discussed in Chapter 1.0, cells exposed to a constant current condition demonstrate a discrete plateau around $2.7 \mathrm{~V}$ [15] and sometimes a second one around 2.1-2.0 V [16, 17], dependent on the cycling rates. The former leveled potential has been associated with the formation of lithium peroxide either via disproportion or reduction of lithium superoxide species [15]. The second plateau observed has been discussed to relate to the reduction of lithium peroxide species $[16,17]$. Figure 3.3 shows a common discharge profile with the associate reactions.

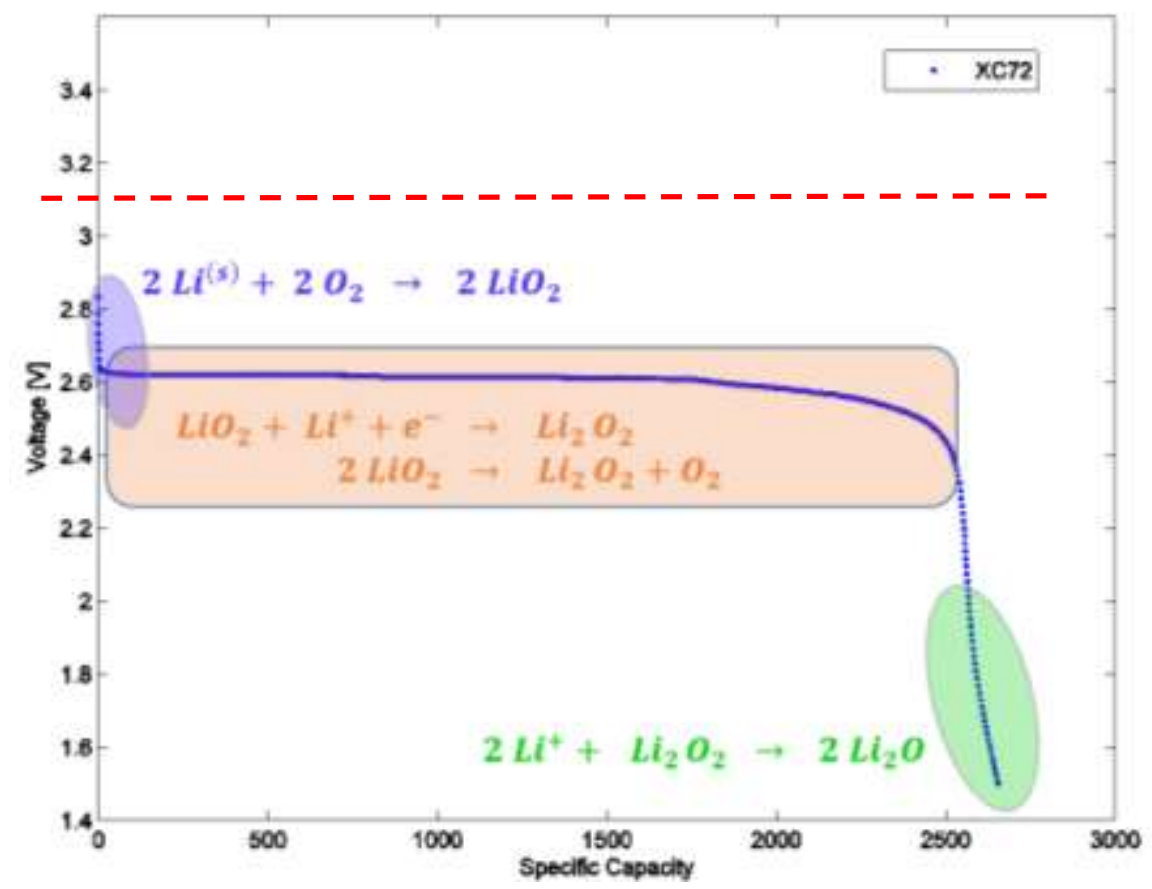

Figure 3.3: Voltage profile of a cell discharged down to $1.5 \mathrm{~V}$ showing the reaction potentials. The dashed red line shows the redox potential of lithium.

The charge profile of lithium-oxygen cells is slightly more challenging to analyze and relate to specific reaction mechanisms. The oxygen evolution reaction (OER) theoretically disassociates lithium peroxide to form oxygen gas and lithium ions. However, side reactions can occur due to the corrosive nature of the oxidation of lithium peroxide [47]. This highly reactive form of oxygen has also more drastic effect with high surface area carbon cathodes [47]. Figure 3.4 demonstrates the charging profile of carbon material XC72 during the first cycle. 


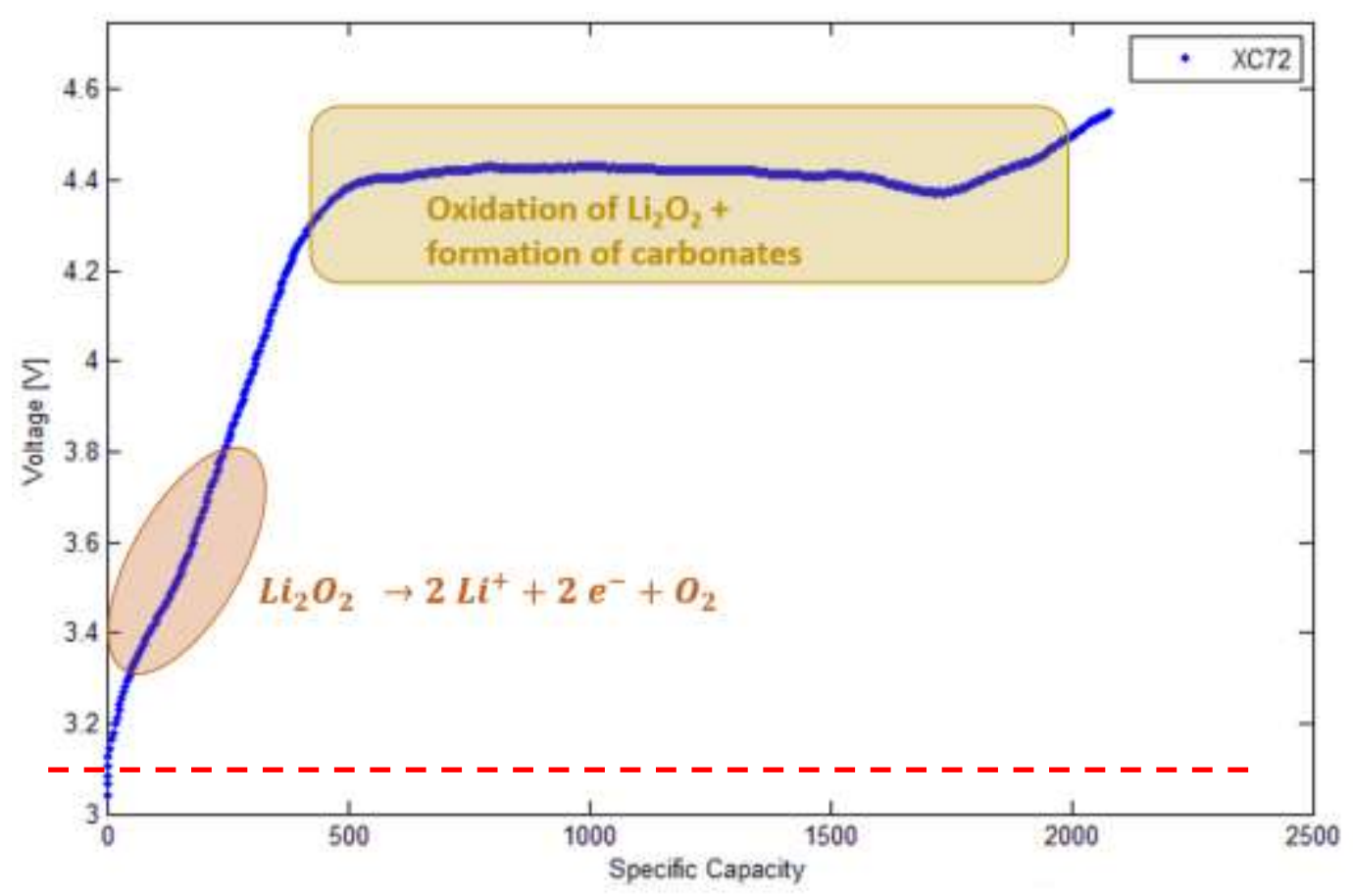

Figure 3.4: Voltage profile of a charge cycle showing the reaction potentials. The dashed red line shows the redox potential of lithium.

In both Figure 3.3 and Figure 3.4, the redox potential $\left(\mathrm{U}_{\mathrm{o}}\right)$ shows the theoretical open circuit voltage of the cell. Comparing that to the discharging and charging plateaus, the initial kinetic resistance as well as the growing exponential resistance at the discharge cycle of the cell can be analyzed. The initial resistance corresponding to the low discharge plateau (compared to $\mathrm{U}_{\mathrm{o}}$ ) is due to diffusion rates of oxygen and lithium ions at a specific current density [13], [48]. The late exponential resistance is associated to the buildup of lithium peroxide reducing the charge transport to the surface layer. On the charge cycle, the general resistance shown from the different of the charging plateau with the redox potential is also associated with the diffusion rates and the formations of insulating side products.

Each cell were cycled with a Landt Instrument battery tester (CT2001A - 5 mA - 5V) at room temperature. The constant current rate used in the entirety of this work was $0.1 \mathrm{mAh} / \mathrm{cm}^{2}$ to reduce the limiting effect of oxygen diffusion, dynamic viscosity or conductivity of the current collector. This value was iterated from findings published in 2006 on the rate capabilities concluding that rates under $0.2 \mathrm{~mA} / \mathrm{cm}^{2}$ had no correlation with those factors [13]. The cut-off voltage for the discharge cycle was set at $2.0 \mathrm{~V}$ to remain consistent with the literature $[5,10$, 49]. The charging cycle was set at the same rate as discharge and the cut-off voltage was set at $4.55 \mathrm{~V}$ to compromising the charging capacity obtained with the voltage window of the electrolyte.

\subsection{IODOMETRIC TITRATION}

The benefit of electrochemical energy storage is the practical efficiency of a specific reversible chemical reaction. As previously discussed, the sought-after product of a lithium-oxygen cell 
reaction is lithium peroxide $\left(\mathrm{Li}_{2} \mathrm{O}_{2}\right)$. However, side reactions have been observed to occur simultaneously and generate irreversible and insulating byproducts - carbonate and hydroxide species [34].

Until recently, the evolution of lithium peroxide was only qualitatively analyzed with various techniques such as scanning electron microscopy (SEM), nuclear magnetic resonance (NMR), Fourier transform infrared spectroscopy (FTIR), X-ray photoelectron spectroscopy (XPS), Raman spectroscopy or X-ray diffraction (XRD) [29, 50]. Although providing information about the overall system, those techniques can only establish whether pure lithium peroxide is present comparatively to other discharge product. In August 2013, McCloskey et al. published about the first time a well-known analytical chemistry technique - hydrogen peroxide titration - was applied to a lithium-oxygen system [41]. Designed to accurately and repeatedly quantify the formation of lithium peroxide in a cycled cell, this technique can be used to gain insights on the overall chemical process and determine the $\mathrm{Li}_{2} \mathrm{O}_{2}$ yield at various cycle.

By exposing a discharge cell to de-ionized water, the highly reactive lithium peroxide will react with water to produce hydrogen peroxide guided by the following reaction (Equation 3-1). McCloskey et al. also discuss the effect of the side reaction shown in Equation 3-2 and the oxygen evolution is concluded to be negligent making the ratio of lithium peroxide to hydrogen peroxide one-to-one.

$$
\begin{gathered}
\mathrm{Li}_{2} \mathrm{O}_{2}+2 \mathrm{H}_{2} \mathrm{O} \rightarrow 2 \mathrm{LiOH}+\mathrm{H}_{2} \mathrm{O}_{2} \\
\mathrm{Li}_{2} \mathrm{O}_{2}+\mathrm{H}_{2} \mathrm{O} \rightarrow 2 \mathrm{LiOH}+\frac{1}{2} \mathrm{O}_{2}
\end{gathered}
$$

Thus, the formed hydrogen peroxide can be titrated very accurately using one of the various titration techniques. Although permanganate titration yields a higher accuracy, iodometric titration is less prone to react with organic solvents - which are used as an electrolyte (glymes, DMSO ,...) in a large number of $\mathrm{LiO}_{2}$ studies - making this technique more adequate for lithium peroxide titration [41].

In presence of an acid and a molybdate catalytic solution, hydrogen peroxide reacts with iodide to form iodine which can afterward be titrated with a thiosulfate solution, as shown in Equations 3-3 and 3-4.

$$
\begin{gathered}
\mathrm{H}_{2} \mathrm{O}_{2}+2 \mathrm{KI}+\mathrm{H}_{2} \mathrm{SO}_{4} \rightarrow \mathrm{I}_{2}+\mathrm{K}_{2} \mathrm{SO}_{4}+2 \mathrm{H}_{2} \mathrm{O} \\
\mathrm{I}_{2}+2 \mathrm{Na}_{2} \mathrm{~S}_{2} \mathrm{O}_{3} \rightarrow \mathrm{Na}_{2} \mathrm{~S}_{4} \mathrm{O}_{6}+2 \mathrm{NaI}
\end{gathered}
$$

With the help of a starch indicator, the titration of iodine undergoes a drastic color change once the iodine has been exhausted completely. Thus, the amount of the thiosulfate solution introduced in the solution is directly related to the quantity of iodine present which is therefore related to the quantity of lithium peroxide originally introduced in the vial.

In the proposed lithium peroxide titration technique, a number of controls were used to identify the accuracy and repeatability of the technique. 
The theoretical quantity of lithium peroxide found in a discharge can be found using Gibbs free energy equation (Equation3-5).

$$
\Delta G=-n F E
$$

Where $\Delta \mathrm{G}$ is Gibbs Free Energy or the energy from the reaction, $\mathrm{n}$ is the number of mole electron participating in the reaction, $F$ is Faraday's constant and $E$ is the potential at which the reaction occurred. This equation can thus be rearranged to assess the theoretical number of moles of lithium peroxide a cell should have produced given the capacity. Thus, the energy in Wh produced by a cell when discharged for $1 \mathrm{mAh}$ is:

$$
\text { Energy }=(\text { Capacity })(\text { Potential })=(-0.001 A h)(E)
$$

Using this Equation (3-6) in Gibbs Free Energy equation, the total number of electron moles can be found as follows:

$$
(-0.001 A h)(E)=-n\left(96,500 \frac{C}{m o l e^{-}}\right)(E)
$$

Equation 3-7 can be solved for $\mathrm{n}$ in $\mu \mathrm{mol} \mathrm{e}^{-}$using the conversion $1 \mathrm{Ah}=3600 \mathrm{C}$. Given a $2 \mathrm{e}^{-}$ /mole $\mathrm{Li}_{2} \mathrm{O}_{2}$ process, the quantity of lithium peroxide present in an ideal lithium-oxygen cell after a discharge capacity of $1 \mathrm{mAh}$ is $\sim 18.6 \mu \mathrm{mol}$. This value can be used to determine the yield of lithium peroxide of various cells.

\subsection{ELECTROCHEMICAL IMPEDANCE SPECTROSCOPY}

The two techniques previously discussed in this chapter only provided a static performance of the different cells. EIS measurements can provide insights on the kinetics of the overall cell at different points of the cycle. When assembled, each element of a cell reacts with one another and form surface layers that affect the overall reaction. In contact with the electrolyte, the lithium will form a thin passive solid electrolyte interface (SEI) layer that protects the lithium from degradation. Understanding the kinetics and their evolution behind the various interfaces can provide great information if combined with the two previously discussed techniques. For instance, the rapidly degrading peroxide yield can be studied with respect to developing internal interfaces.

Electrochemical impedance spectroscopy is a highly versatile analytical technique that has been applied to various types of system studies such as corrosion rates, interface reactions, mass transport and other reaction parameters. Based on Ohms' law $(Z=E / I$, where $Z$ is impedance, $E$ is potential, and $\mathrm{I}$ is current), a system is exposed to a series of sinusoidal signals over a specific range of frequencies and the response feedback is used to calculate the impedance of the system at that frequency. Combining both a real (resistance) and imaginary (capacitive and inductive) value, the impedances collected through this process can be plotted in a Nyquist plot and analyzed to find an equivalent circuit model. Based on the model, the kinetic parameters of various interfaces can be monitored as they vary within the system. This in-situ technique tested in its environment - is especially powerful when associated with other techniques. Thus, 
the purpose of this analysis in this work is to monitor the evolution of interfaces as a cell is cycled and correlate any observations to the lithium peroxide yield from the cell.

Two types of EIS testing techniques can be used: galvanostatic and potentiostatic EIS. The GEIS test will expose the sample to a sinusoidal voltage at a certain magnitude around a constant value and the response current is measured to acquire the impedance data point. On the other hand, a PEIS test will input a sinusoidal current of a certain magnitude around a specific value - either zero or at constant current - while recording the response voltage.

In the battery field, EIS has been utilized on a laboratory level to study the internal impedances evolution and correlate them to the deterioration of capacity [51]. More specifically, impedance spectroscopy has been used in prototype cell to assess the health of the battery at various cycles [52]. In the case of lithium-oxygen cells, EIS has been explored to assess the development of impeding layers within the cells $[48,51,53-55]$. As expected, the SEI layer forming on the lithium and the ionic transport to the cathode has the most obvious effect $[51,53]$. The three major impedances found in the discussed lithium-oxygen cell are the electrolyte resistance, the SEI resistance and the mass transport resistance [53]. These impedances will increase throughout cycling $[51,54]$ and associating it with internal reactions can help understand the properties of the side products formed. By correlating the evolution of those impedances, a correlation with the quantity of lithium peroxide present in a discharge cell can be pursued.

Since a Swagelok cell is being used in this study, it is crucial to understand the overall impedance of the body of the cell. Each connection within the design of the cell was modelled as shown in Figure 3.5.

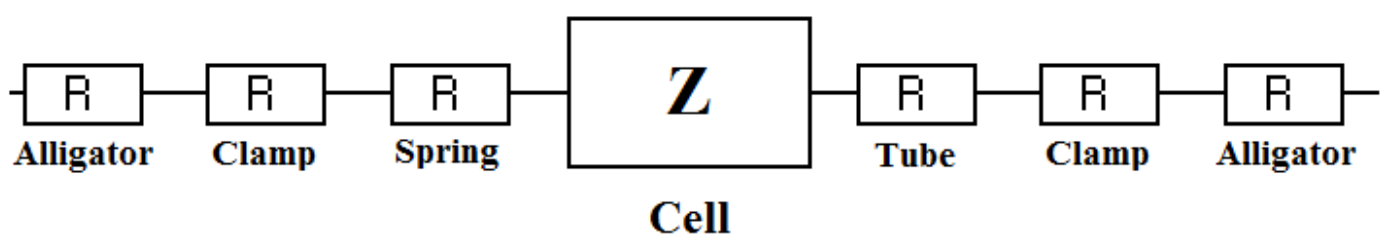

Figure 3.5: Equivalent circuit of all connections in an assembled Swagelok cell

Thus, a number of controls were performed to assess the contact resistance between each cell:

1. The first control that was run on the cell assembly was the impedance due to the alligator clips from the instrument and the stainless steel hose clamps on each electrode contact. To characterize this value, two hose clamps were attached on a single SS rod. The impedance found from all those connections was found to be between $0.03 \Omega$ and $0.06 \Omega$. The variation was due to the alligator clip connection and is considered as negligible compared to other values.

2. The second control was used to characterize the impedance due to the spring connection. A stainless steel rod was used for each electrode in a Swagelok cell. A wide window of value was found varying from $0.354 \Omega$ to $3.5 \Omega$. The lower value was found in a cell that was compressed to its maximum and the lower value was found in a cell with little 
pressure. The resistance found in the spring compressed that would simulate the compression of a full cell was found to be on average $0.5 \Omega$.

3. The last control characterizes the resistance between the tube and the cell. Since limited surface area is connected to the rest of the cell, the resistance is significantly higher. The impedance found between a stainless steel disk and the SS tube was on average $6.25 \Omega$. Since those two pieces have very high tensile strength which may not simulate the porous carbon cathode, a carbon paper layer was added to the control and the resistance was found to increase slightly $(7.5 \Omega)$. This may be due to the additional resistance between the SS disk and the carbon paper.

With a better understanding of the base-line impedances present in the cell, it is possible to propose a model of the lithium oxygen cell to further understand the reaction mechanisms and layer formation evolution. 


\subsection{RESULTS AND DISCUSSION}

This section provides a general scope of the results and discussion of the battery cells testing performed in the experimental setup described in section 2.0. At the moment of the preparation of this report, this study has concluded but specific details will be published in a MS thesis entitled: "Characterization of Lithium peroxide formation in lithium air electrode via titration techniques and EIS". This work will be defended on July 7, 2014. Final revisions will be due at the end of Summer 2014. Results of this work will also be submitted for publication in a peerreviewed journal.

\subsection{GALVANOSTATIC CYCLING RESULTS}

As previously discussed in Chapter 3.0, this test was conducted to assess the raw performance of various carbon materials in lithium oxygen batteries. Five carbon materials were tested to determine their effective capacity and their voltage profile at which the main reaction occurs. No additional mediators or catalyzers were used in the cells in order to be able to assess and compare the performance of the carbon material alone. At least three specimens were tested for each sample to determine repeatability in the testing. The galvanostatic testing was pursued for the first, second and third cycles to assess the performance of the carbon cathode and to determine if repeatable cycling can be performed. This test has even more relevance once compared to the other two tests conducted in this work.

\subsection{IODOMETRIC TITRATION RESULTS}

The previous section discusses the total capacity drawn from each cells with the various carbon cathodes. Furthermore, it discusses the performance of the chemistry and slightly investigates its reversibility. However, the performance of the battery is only assessed on its overall performance and not on the performance of the controlled reaction (i.e. formation of lithium peroxide). As lithium oxygen batteries features a reaction between lithium and oxygen in a controlled and reversible manner, a relatively stable and reversible byproduct of that reaction is lithium peroxide. Therefore, quantifying the yield of $\mathrm{Li}_{2} \mathrm{O}_{2}$ after discharging a cell can provide a true assessment on the performance of the sample. Furthermore, as part of the scope of work of this thesis, the performance of the various carbon cathodes were tested to determine the lithium peroxide yield at different cycles, cell composition and testing conditions.

\subsection{ELECTROCHEMICAL IMPEDANCE SPECTROSCOPY RESULTS}

When defining the scope of this work, electrochemical impedance spectroscopy was a technique that was suggested to further understand the reaction mechanism inside a cell and to correlate internal impedance evolution with the formation of lithium peroxide in $\mathrm{Li}-\mathrm{O}_{2}$ batteries. Therefore, cell impedances were acquired on each specimen both in their pristine and terminated state. 


\subsection{REFERENCES}

[1] G. Craptree, "JCESR: One Year Later," in Material Research Society, 2014.

[2] ARPAE, “Advanced Research Projects Agency - Energy,” 2014. [Online]. Available: http://arpa-e.energy.gov/.

[3] ARPAE, "Batteries for Electrical Energy Storage in Transportation," 2014. [Online]. Available: http://arpa-e.energy.gov/?q=arpa-e-programs/beest.

[4] T. Reddy, Linden's Handbook of Batteries, 4th Edition. 2010, p. 1200.

[5] J. Christensen, P. Albertus, R. S. Sanchez-Carrera, T. Lohmann, B. Kozinsky, R. Liedtke, J. Ahmed, and A. Kojic, "A critical review of Li/air batteries," J. Electrochem. Soc., vol. 159, no. 2, pp. R1 - R30, 2012.

[6] D. Linden and T. B. Reddy, HANDBOOK OF BATTERIES, 3rd Editio. McGraw-Hill.

[7] J. B. Goodenough and Y. Kim, "Challenges for rechargeable batteries," J. Power Sources, vol. 196, no. 16, pp. 6688-6694, Aug. 2011.

[8] J. B. Goodenough, "Cathode materials: A personal perspective," J. Power Sources, vol. 174, no. 2, pp. 996-1000, Dec. 2007.

[9] J. P. Zheng, R. Y. Liang, M. Hendrickson, and E. J. Plichta, "Theoretical energy density of Li-air batteries," J. Electrochem. Soc., vol. 155, no. 6, pp. A432 - A437, 2008.

[10] G. Girishkumar, B. McCloskey, a. C. Luntz, S. Swanson, and W. Wilcke, "Lithium-air battery: Promise and challenges," J. Phys. Chem. Lett., vol. 1, no. 14, pp. 2193-2203, Jul. 2010.

[11] J. Dahn, "Electrically Rechargeable Metal-air Batteries Compare to Advanced Lithiumion Batteries," 2011, pp. 1-52.

[12] N. Zhao, L. Fu, L. Yang, T. Zhang, G. Wang, Y. Wu, and T. van Ree, "Nanostructured anode materials for Li-ion batteries," Pure Appl. Chem., vol. 80, no. 11, pp. 2283-2295, Jan. 2008.

[13] J. Read, "Ether-based electrolytes for the lithium/oxygen organic electrolyte battery," J. Electrochem. Soc., vol. 153, no. 1, pp. A96 - A100, 2006.

[14] C. O. Laoire, S. Mukerjee, K. M. Abraham, E. J. Plichta, and M. A. Hendrickson, "Influence of nonaqueous solvents on the electrochemistry of oxygen in the rechargeable lithium- air battery," J. Phys. Chem. C, vol. 114, no. 19, pp. 9178-9186, 2010. 
[15] S. a Freunberger, Y. Chen, N. E. Drewett, L. J. Hardwick, F. Bardé, and P. G. Bruce, "The lithium-oxygen battery with ether-based electrolytes.," Angew. Chem. Int. Ed. Engl., vol. 50, no. 37, pp. 8609-13, Sep. 2011.

[16] S. S. Zhang, D. Foster, and J. Read, "A high energy density lithium/sulfur-oxygen hybrid battery,” J. Power Sources, vol. 195, no. 11, pp. 3684-3688, Jun. 2010.

[17] S. S. Zhang, D. Foster, and J. Read, "Discharge characteristic of a non-aqueous electrolyte Li/O2 battery," J. Power Sources, vol. 195, no. 4, pp. 1235-1240, Feb. 2010.

[18] K. M. Abraham and Z. Jiang, "Polymer electrolyte-based rechargeable lithium/oxygen battery," J. Electrochem. Soc., vol. 143, no. 1, pp. 1-5, 1996.

[19] T. Ogasawara, A. Debart, M. Holzapfel, P. Novak, and P. G. Bruce, "Rechargeable Li2O2 electrode for lithium batteries," J. Am. Chem. Soc., vol. 128, no. 4, pp. 1390-1393, 2006.

[20] F. Mizuno, S. Nakanishi, Y. Kotani, S. Yokoishi, and I. Hideki, "Rechargeable li-air batteries with carbonate-based liquid electrolytes," in Electrochemistry, 2010, vol. 78, no. 5, pp. 403-405.

[21] N. Imanishi, S. Hasegawa, T. Zhang, A. Hirano, Y. Takeda, and O. Yamamoto, "Lithium anode for lithium-air secondary batteries," J. Power Sources, vol. 185, no. 2, pp. 13921397, Dec. 2008.

[22] G. Yu. Aleshin, D. A. Semenenko, A. I. Belova, T. K. Zakharchenko, D. M. Itkis, E. A. Goodilin, and Y. D. Tretyakov, "Protected anodes for lithium-air batteries," Solid State Ionics, vol. 184, pp. 62-64, 2011.

[23] T. Zhang, N. Imanishi, S. Hasegawa, A. Hirano, J. Xie, Y. Takeda, O. Yamamoto, and N. Sammes, "Water-Stable Lithium Anode with the Three-Layer Construction for Aqueous Lithium-Air Secondary Batteries," Electrochemical and Solid-State Letters, vol. 12. p. A132, 2009.

[24] A. Kraytsberg and Y. Ein-Eli, "Review on Li-air batteries - Opportunities, limitations and perspective,” J. Power Sources, vol. 196, no. 3, pp. 886-893, 2011.

[25] B. D. McCloskey, A. Speidel, R. Scheffler, D. C. Miller, V. Viswanathan, J. S. Hummelshøj, J. K. Nørskov, and A. C. Luntz, "Twin Problems of Interfacial Carbonate Formation in Nonaqueous Li-O 2 Batteries," J. Phys. Chem. Lett., vol. 3, no. 8, pp. 9971001, Apr. 2012.

[26] Y.-C. Lu, B. M. Gallant, D. G. Kwabi, J. R. Harding, R. R. Mitchell, M. S. Whittingham, and Y. Shao-Horn, "Lithium-oxygen batteries: bridging mechanistic understanding and battery performance," Energy Environ. Sci., vol. 6, no. 3, p. 750, 2013.

[27] E. Nasybulin, W. Xu, M. H. Engelhard, Z. Nie, S. D. Burton, L. Cosimbescu, M. E. Gross, and J. Zhang, "Effects of electrolyte salts on the performance of Li-O2 batteries," J. Phys. Chem. C, vol. 117, no. 6, pp. 2635-2645, 2013. 
[28] W. Walker, V. Giordani, J. Uddin, V. S. Bryantsev, G. V Chase, and D. Addison, “A Rechargeable Li - O 2 Battery Using a Lithium Nitrate /," J. Am. Chem. Soc., vol. 135, pp. 3-6, 2013.

[29] B. D. Adams, C. Radtke, R. Black, M. L. Trudeau, K. Zaghib, and L. F. Nazar, "Current density dependence of peroxide formation in the Li-O2 battery and its effect on charge," Energy Environ. Sci., vol. 6, p. 1772, 2013.

[30] B. D. McCloskey, D. S. Bethune, R. M. Shelby, G. Girishkumar, and A. C. Luntz, "Solvents critical role in nonaqueous Lithium-Oxygen battery electrochemistry," J. Phys. Chem. Lett., vol. 2, pp. 1161-1166, 2011.

[31] W. Xu, J. Hu, M. H. Engelhard, S. A. Towne, J. S. Hardy, J. Xiao, J. Feng, M. Y. Hu, J. J. Zhang, F. Ding, others, and M. E. Gross, "The Stability of Organic Solvents and Carbon Electrode in Nonaqueous Li-O $<\mathrm{sub}>2</$ sub $>$ Batteries," J. Power Sources, vol. 215, pp. 240-247, 2012.

[32] C. Ó. O. Laoire, S. Mukerjee, E. J. Plichta, M. A. Hendrickson, and K. M. Abraham, "Rechargeable lithium/TEGDME-LiPF6/O2 battery," J. Electrochem. Soc., vol. 158, no. 3, pp. A302-A308, 2011.

[33] Z. Peng, S. a Freunberger, Y. Chen, and P. G. Bruce, "A reversible and higher-rate Li-O2 battery.," Science, vol. 337, no. 6094, pp. 563-6, Aug. 2012.

[34] M. M. Ottakam Thotiyl, S. a Freunberger, Z. Peng, and P. G. Bruce, "The carbon electrode in nonaqueous Li-O2 cells.," J. Am. Chem. Soc., vol. 135, no. 1, pp. 494-500, Jan. 2013.

[35] S. Meini, M. Piana, H. Beyer, J. Schwammlein, and H. a. Gasteiger, "Effect of Carbon Surface Area on First Discharge Capacity of Li-O2 Cathodes and Cycle-Life Behavior in Ether-Based Electrolytes," J. Electrochem. Soc., vol. 159, no. 12, pp. A2135-A2142, Oct. 2012.

[36] J.Read and J. Read, "Characterization of the lithium/oxygen organic electrolyte battery," J. Electrochem. Soc., vol. 149, no. 9, pp. A1190 - A1195, 2002.

[37] J. Xiao, D. Wang, W. Xu, D. Wang, R. E. Williford, J. Liu, and J.-G. Zhang, "Optimization of Air Electrode for Li'Air Batteries," J. Electrochem. Soc., vol. 157, no. 4, pp. A487-A492, 2010.

[38] J. Xiao, D. Mei, X. Li, W. Xu, D. Wang, G. L. Graff, W. D. Bennett, Z. Nie, L. V Saraf, I. a Aksay, J. Liu, and J.-G. Zhang, "Hierarchically porous graphene as a lithium-air battery electrode," Nano Lett., vol. 11, no. 11, pp. 5071-5078, 2011.

[39] D. Wang, J. Xiao, W. Xu, and J.-G. Zhang, "High capacity pouch-type Li-air batteries," J. Electrochem. Soc., vol. 157, no. 7, pp. A760 - A764, 2010.

[40] P. G. Bruce, Y. Chen, L. Johnson, C. Li, Z. Liu, S. a Freunberger, M. M. Ottakam Thotiyl, and Z. Peng, "The Rechargeable Aprotic Lithium-O2 Battery," in RS Spring Meeeting \& Exhibit, 2014. 
[41] B. D. McCloskey, A. Valery, A. C. Luntz, S. R. Gowda, G. M. Wallraff, J. M. Garcia, T. Mori, and L. E. Krupp, "Combining Accurate O2 and Li2O2 Assays to Separate Discharge and Charge Stability Limitations in Nonaqueous Li-O2 Batteries," J. Phys. Chem. Lett., vol. 4, pp. 2989-2993, 2013.

[42] Innovative Technology, "Glovebox Glove Material Compatibility Guide," Glovebox Glove Material Compatibility Guide - White Paper. [Online]. Available:

www.isolatorgloves.com/docs/Material-Compatibility.pdf.

[43] G. S. Chai, S. B. Yoon, J.-S. Yu, J.-H. Choi, and Y.-E. Sung, "Ordered Porous Carbons with Tunable Pore Sizes as Catalyst Supports in Direct Methanol Fuel Cell," J. Phys. Chem. B, vol. 108, no. 22, pp. 7074-7079, Jun. 2004.

[44] X. L. Wang, H. M. Zhang, J. L. Zhang, H. F. Xu, Z. Q. Tian, J. Chen, H. X. Zhong, Y. M. Liang, and B. L. Yi, "Micro-porous layer with composite carbon black for PEM fuel cells,” Electrochim. Acta, vol. 51, no. 23, pp. 4909-4915, Jun. 2006.

[45] N. Tachikawa, K. Yamauchi, E. Takashima, J.-W. Park, K. Dokko, and M. Watanabe, "Reversibility of electrochemical reactions of sulfur supported on inverse opal carbon in glyme-Li salt molten complex electrolytes.," Chem. Commun. (Camb)., vol. 47, no. 28, pp. 8157-9, Jul. 2011.

[46] S. D. Beattie, D. M. Manolescu, and S. L. Blair, "High-capacity lithium--air cathodes," J. Electrochem. Soc., vol. 156, no. 1, pp. A44-A47, 2009.

[47] L. Wang, M. Ara, K. Wadumesthrige, S. Salley, and K. Y. S. Ng, "Graphene nanosheet supported bifunctional catalyst for high cycle life Li-air batteries," J. Power Sources, vol. 234, pp. 8-15, Jul. 2013.

[48] X. H. Yang and Y. Y. Xia, "The effect of oxygen pressures on the electrochemical profile of lithium/oxygen battery,” J. Solid State Electrochem., vol. 14, pp. 109-114, 2010.

[49] Y. Chen, S. A. Freunberger, Z. Peng, O. Fontaine, and P. G. Bruce, "Charging a Li - $\mathrm{O}_{2}$ battery using a redox mediator," vol. 5, no. June, pp. 1-6, 2013.

[50] R. R. Mitchell, B. M. Gallant, Y. Shao-Horn, and C. V. Thompson, "Mechanisms of morphological evolution of Li2O2 particles during electrochemical growth," J. Phys. Chem. Lett., vol. 4, pp. 1060-1064, 2013.

[51] M. Mirzaeian and P. J. Hall, "Characterizing capacity loss of lithium oxygen batteries by impedance spectroscopy,” J. Power Sources, vol. 195, no. 19, pp. 6817-6824, Oct. 2010.

[52] S. Rodrigues, N. Munichandraiah, and A. K. Shukla, "Review of state-of-charge indication of batteries by means of a.c. impedance measurements," J. Power Sources, vol. 87, pp. 12-20, 2000.

[53] J. Adams, M. Karulkar, and V. Anandan, "Evaluation and electrochemical analyses of cathodes for lithium-air batteries," J. Power Sources, vol. 239, no. 0, pp. 132-143, Oct. 2013. 
[54] M. Eswaran, N. Munichandraiah, and L. G. Scanlon, "High capacity $\mathrm{Li}_{-} \mathrm{O}_{2}$ cell and electrochemical impedance spectroscopy study," Electrochem. Solid-State Lett., vol. 13, no. 9, pp. A121 - A124, 2010.

[55] J. Kumar and B. Kumar, "Development of membranes and a study of their interfaces for rechargeable lithium-air battery," J. Power Sources, vol. 194, no. 2, pp. 1113-1119, Dec. 2009. 
Transportation Research and Education Center

Portland State University

1900 S.W. Fourth Ave., Suite 175

Portland, OR 97201 